\title{
As coleções Kaingang, Guarani Nhandewa e Terena - Percurso documental, requalificação e colaboração'
}

\author{
The Kaingang, Guarani Nhandewa and Terena collections - Documentary journey, \\ requalification and collaborative process
}

hitps://doi.org/10.1590/1982-02672021v29e6

\author{
MARILIA XAVIER CURY² \\ https:/ / orcid.org/0000-0002-4661-9525 \\ Universidade de São Paulo / São Paulo, SP, Brasil
}

RESUMO: Este artigo trata de um estudo de curadoria de objetos e coleções Kaingang, Guarani Nhandewa e Terena em São Paulo, com o propósito de informar esses grupos sobre o que os museus - Paulista e de Arqueologia e Etnologia - fizeram por mais de um século (no caso de objetos Kaingang) ou sete décadas (coleções Kaingang, Guarani Nhandewa e Terena). Para se traçar as trajetórias desses objetos e coleções, a estratégia foi recorrer à Revista do Museu Paulista, inventários antigos e outros documentos, para ver o percurso documental e físico dos objetos, por grupo. Na sequência, com a curadoria dos indígenas, são incorporadas novas interpretações aos objetos, a autorrepresentação indígena, contrastando com o processo documental (representação etnográfica). Nesse sentido, temos o objetivo de registrar as entradas e permutas em dado tempo, mas também revelar como a documentação e suas linguagens foram se alterando ou incorporando outras informações, com as implicações devidas, para se chegar aos objetos e a novas interpretações. $\bigcirc$ pano de fundo é a cena descolonial sustentada em processo de colaboração com indígenas, o que levou a pesquisa a entender ações institucionais sucessivas, mas, principalmente, encontrar os objetos e disponibilizá-los aos indígenas com as informações e materialidades preservadas possíveis, para serem apropriadas pelos grupos.

PALAVRAS-CHAVE: Curadoria. Gestão de coleções. Requalificação de coleções. Coleções Kaingang, Guarani Nhandewa e Terena/SP.

\begin{abstract}
1. Artigo readequado e ampliado de CURY, M. X. Requalificação de coleções - processos colaborativos em museu universitário e protagonismo indígena: Uma experiência no $\mathrm{Mu}$ seu de Arqueologia e Etnologia - MAE-USP. In: GROSSI, M. P.; SILVA, S L. et al. (orgs.). Conference Proceedings Anais $-18^{\text {th }}$ IUAES Word Congress, Florianópolis: Tribo da Ilha, 2018b. p. 4404-4410.

2. Docente em Museologia no Museu de Arqueologia e Etnologia, Universidade de São Paulo. Coordenadora do InterMuseologias - Laboratório Interfaces entre $\mathrm{Mu}$ seologias - Comunicação, Mediação, Públicos e Recepção. Desde 2010 se dedica a estudar a relação entre museus e indígenas por meio de ações em colaboração, reconhecendo os direitos indígenas à musealização. E-mail: <maxavier@usp.br>.
\end{abstract}


ABSTRACT: The article deals with a study of curatorship of Kaingang, Guarani Nhandewa and Terena collections in São Paulo, with the purpose of informing these groups about what museums - Paulista and Archeology and Ethnology - have done for more than a century (in the case of Kaingang objects) or seven decades (Kaingang, Guarani Nhandewa and Terena collections). In order to trace the trajectories of these objects and collections, the strategy was to resort to Revista do Museu Paulista, old inventories and other documents, to follow the documentary and physical path of the objects by group. Then, with the curatorship of the indigenous people, new interpretations of the objects are incorporated, contrasting with the documentary process (ethnographic representation) and indigenous self-representation. Therefore, we aim to record the entries and exchanges at a given time, but also to reveal how the documentation and its languages have been changing or incorporating other informations, with its necessary implications, until reaching the objects. The backdrop is the decolonial scene sustained in collaboration processes with indigenous people, which led the research to understand the successive institutional actions, but mainly, to find the objects and make them available to the indigenous people with the possible information and materialities preserved, to be appropriated by groups.

KEYWORDS: Curatorship. Collections management. Collection requalification. Collections Kaingang, Guarani Nhandewa and Terena/SP. 
INTRODUÇÃO

Museu de Arqueologia e Etnologia da Universidade de São Paulo (MAE-USP) foi criado em 1989 pela reunião dos acervos de arqueologia e etnologia da USP, até então sob a guarda do antigo MAE, Museu Paulista, Instituto de Pré-História Paulo Duarte e Acervo Plinio Ayrosa da Faculdade de Filosofia, Ciências e Letras. As coleções etnográficas do MAE-USP remontam há mais 100 anos, grande parte delas procede do Museu Paulista (MP-USP). Num dos museus mais antigos do Brasil, o MP-USP, entraram coleções etnográficas de várias partes do território brasileiro e paulista, desde antes da inauguração em 1895, com a coleção particular do Coronel Joaquim Sertorio. ${ }^{3}$

Muitos foram os coletores nacionais e internacionais que fazem parte da constituição das coleções indígenas do MP-USP que merecem ser mencionados: Adalbert H. Pereira, Albert V. Fric, Antonio Kanajó Kirimida, B. Loebens, Benedito Calixto, Benedito Estelita Alvares, Borys Malkin, Candido M. S. Rondon e a Comissão Rondon, Claude Lévi-Strauss, C. Hermann Hofbaver, Curt Nimuendaju, Darcy Ribeiro, David Maybury-Lewis, Delvair Montagner, Desidério Aytai, Egon Schaden, Erich Freundt, Ernesto Garbe, Ernesto Glawe, Eurico de M. C. Fernandes, Expedição Bandeira Anhagüera, Franz Adam, George Gottfried Grünberg, Franz Heger, Friedrich C. Mayntzhusen, Gil Vilanova, Harald Schultz, Harald Schultz e Vilma Chiara, Hans Becher, Herbert Baldus, Lux Vidal, José Bach, Mário D. Andreucci, Nobue Myazaki, Odilon J. de Souza Filho, Paulo E. Vanzolini, Protásio Frikel, Raimundo G. H. Caron, Raymundo N. Miranda, Sônia T. Ferraro Dorta, Tekla Hartmann, Themistocles P. S. Brasil, Valdemar Salina, Vilma Chiara, Wanda Hanke, Werner C. A. Bockermann, Wili Tiede, William H. Crocker, Winfield L Buckman. ${ }^{4}$ Essa relação faz parte do artigo de Sergio Damy e Thekla Hartmann publicado na Revista do Museu Paulista, nela constam os povos indígenas, as regiões e anos de coleta, tentativas de indicar os números de registros dos objetos museológicos, para organização das coleções, parte do projeto Coleções etnográficas brasileiras: histórico e composição. Os autores apresentam os perfis bio-bibliográficos dos coletores.

Informações como essas e outras relativas à entrada, formação e permutas de coleções faziam parte dos relatórios anuais e artigos da Revista do Museu Paulista (1895 a 1938) e da nova série que a sucedeu (1947 a 1987). Os relatórios foram esforços de registrar e informar, como os diversos textos publicados no periódico indicavam marcos políticos do Museu Paulista e posicionamentos científicos. Após a fusão das coleções arqueológicas e etnográficas da USP que gerou o MAE-USP, esses registros e artigos no periódico ainda são consultados,
3. "Só em 1894 com a nomeação do Snr. Dr. Hermann von Ihering para director do Museu Paulista, teve o Monumento seu aproveitamento definitivo. Para ahi passou-se, o que aproveitavel fosse, do chamado Museu Sertorio, offerecido am [sic] 1890 pelo Cons.o Mayrink ao Governo do Estado." In: Museu Paulista (1907), Guia pelas collecções do Museu Paulista.

4. Damy; Hartmann (1986, p. 223-246). Essa relação é apresentada no artigo $A s$ coleções etnográficas do Museu Paulista: composição e história (p. 220-267), em um extenso quadro com as colunas Etnia, Localização, Coletor, Ano, N. ${ }^{\circ} \mathrm{Pe}-$ ças, Observações. Nos dois últimos itens temos a quantidade e indicações da natureza do artefato e RG. As entradas mais antigas constam como 1903, compra de Benedito Estelita Alvares, Bororo, Mato Grosso, e Jívaro, Equador. 
5. Paulo DeBlasis e Walter Morales realizaram trabalho semelhante relatado em $O$ potencial dos acervos antigos: recuperando a coleção o3o do Museu Paulista (1997): "Foi concebido como um estudo de curadoria, uma colaboração no esforço institucional de recuperar e organizar as velhas coleções envolvidas na fusão dos museus da USP em 1989 [...]" (p. 111).

6. Sujeitos cujas culturas se relacionam com as coleções sob salvaguarda institucional. Cury (2020b).

7. Finalidade que se assemelha ao objetivo em DeBlasis; Morales (1997, p. 112): "Recuperar, na medida do possível, a história da formação de coleção e a documentação pertinente, o que significa na prática investigar a história das práticas museológicas adotadas pelo Museu Paulista ao longo dos seus mais de 100 anos de vida."

8. DeBlasis e Morales (1997, p. 112) fizeram percurso contrário, partiram da coleção e suas peças, para, a partir de inscrições, buscar a documentação relacionada. "Com isto, foi possível gerar um controle preciso das peças que compõem a coleção, sua quantidade e características, assim como registrar a história museológica impressas nas sucessivas recatalogações pelas quais muitas delas passaram, o que por sua vez foi o ponto de partida para as investigações documentais realizadas na sequência.”

9. Velthem; Kukawka; Joanny (2017).

10. Roca (2015a). O conceito de indigenização refere-se às formas de apropriação do museu pelos indígenas, seja participando de ações de musealização em museus tradicionais, seja criando museus indígenas. Roca para a gestão das coleções, cruzando as informações que foram difundidas no passado com os sucessivos inventários, documentos de entrada, fichas catalográficas e demais informações disponíveis na documentação museológica do museu.

Este artigo reconhece a importância dos arquivos documentais das instituições que geraram coleções, como também quer valorizar os periódicos institucionais que ainda nos permitem pesquisas de diversas vertentes, na ótica da interdisciplinaridade em museologia.

Hoje, essas consultas cruzadas tornam-se essenciais para a organização do sistema documental e catalogação das coleções, mas também para estudos de curadoria de coleções, ${ }^{5}$ elaboração de exposições e requalificação das coleções, quando grupos indígenas buscam os objetos de seus antepassados e seus direitos à participação no processo de musealização como constituintes e curadores. ${ }^{6}$ Nesse sentido, este artigo trata de um levantamento realizado para localização de objetos relacionados aos Kaingang, Guarani Nhandewa e Terena em São Paulo, com o propósito de informar esses grupos sobre o que os museus - Paulista e de Arqueologia e Etnologia - fizeram por mais de um século (no caso de objetos Kaingang) ou sete décadas (coleções Kaingang, Guarani Nhandewa e Terena). Para se traçar as trajetórias desses objetos e coleções, para colocá-los diante dos seus herdeiros por direito, a estratégia foi recorrer à Revista do Museu Paulista, inventários antigos e outra documentação, para ver o percurso documental e físico dos objetos - a trajetória do objeto -, por grupo. Nesse sentido, temos o objetivo de registrar as entradas e permutas em dado tempo, mas também revelar como a documentação e suas linguagens foram se alterando ou incorporando novas informações, com as implicações devidas, ${ }^{7}$ para se chegar aos objetos. ${ }^{8}$

Revisitando o passado do MP-USP por meio de objetos e coleções de três grupos indígenas de São Paulo, para refletir sobre questões atuais, o que vimos tratar são as recentes transformações que abrem os museus às perspectivas dos direitos e dos movimentos reivindicatórios indígenas, fortemente acentuadas no Brasil após a Constituição de 1988.

Entre os direitos indígenas a seus patrimônios outrora musealizados, aqui entendidos como coleções etnográficas, ${ }^{9}$ e as transformações dos campos antropológico e museológico está o museu atual que se enfrenta, para cumprir uma nova agenda com os indígenas. Os grandes desafios museais para os próximos anos é a indigenização ${ }^{10}$ do museu e descolonização do pensamento que envolve a gestão institucional. Nesse sentido, entre tantos pontos a serem abordados, as coleções, como âmago do museu, são reorganizadas, na ótica da gestão de coleções, e reestudadas, mediante procedimentos curatoriais. 
Anteriormente, os antropólogos do Museu Paulista Damy e Hartmann, observaram:

O estudo das expressões materiais de culturas indígenas é um dos aspectos mais negligenciados na pesquisa etnológica, em grande parte devido à falta de informação sobre as coleções etnográficas existentes nos museus, especializados ou não. $\bigcirc$ interessado deve bater de porta em porta nessas instituições para verificar pessoalmente se armazenam materiais significativos para o trabalho a que se propõe. Artefatos indígenas brasileiros vêm sendo recolhidos desde 1500, mas o pesquisador não dispõe de uma obra de referência que o oriente quanto à sua localização, proveniência, número, condições de coleta, em resumo, sobre o seu potencial de pesquisa. ${ }^{11}$

Mais de 30 anos após a publicação dessa afirmativa na Revista do Museu Paulista, ainda seguimos na organização das coleções, a constatação é atual, mesmo considerando o trabalho já realizado por muitos nos museus universitários e etnográficos. ${ }^{12}$ Soma-se ao fato de que com a TIC - Tecnologia da Informação e Comunicação novas operações trazem novas pautas museográficas, mas que só veem a apoiar o básico sobre as coleções, uma "obra de referência que o oriente [o usuário] quanto à sua localização [do objeto], proveniência, número, condições de coleta, em resumo, sobre o seu potencial de pesquisa". ${ }^{13}$ Enfim, temos muito trabalho a fazer.

$\bigcirc$ pano de fundo que trazemos para a discussão é a cena descolonial que questiona, mas também propõe novas práticas em museus que envolvem coleções etnográficas:

What kind of meaning does one want to produce today on the basis of such collections, collections that appear to have reached the dead-end of research? What role do they play in relation to universities? What modus operandi can be introduced today so that these heteroclite, anachronistic objects from the past are recharged with contemporary meanings? If museums have to fight against routine, habit, and conservatism, what kind of working method can we develop to reactivate the reservoirs they hold once more? ${ }^{14}$

A experiência que se realiza no MAE-USP trazida para este artigo está baseada em processo de colaboração com os Kaingang, Guarani Nhandewa e Terena, o que levou o estudo de curadoria a entender ações institucionais sucessivas que envolveram as coleções, mas, principalmente, encontrar os objetos e disponibilizá-los aos indígenas com as informações e materialidades preservadas possíveis. $\bigcirc$ propósito da colaboração é demonstrar como diferentes perspectivas, (2015a) apresenta as duas possibilidades, contextualizando a indigenização no museus indígena e tradicional em decorrência dos movimentos civis pós década de 1970 e o estabelecimento de políticas públicas.

11. Damy; Hartmann (1986, p. 220).

12. Sobre um panorama, cf. Cury (2017b).

13. Damy; Hartmann, (1986, p. 220).

14. Dellis (2015, p. 28). 
15. Colaboração é um método de pesquisa sob revisão crítica, como o artigo de Andrea Roca (2015b), como também descrições analíticas de práticas, como Silva, 2015, Silva, 2012, Cury (2020b), Cury (2019a).

16. Sobre termos, conceitos e práxis em museus, cf. Dossiê "Patrimônio indígena e coleções etnográficas" organizado por Françozo e Broekhoven (2017) com as contribuições de Garcés; Françozo; Broekhoven; Ka'apor, Velthem; Kukawka; Joanny, e Shepard Jr.; Garcés; Robert; Chaves.

17. Associação Brasileira de Antropologia (ABA), por meio do Comitê de Patrimônios e Museus, desde 2018 mantém o projeto Mapeamento de Coleções Etnográficas no Brasil.

18. Os contatos e sucessão de ações acontecem desde 2010, o que permitiu uma troca e mútuos conhecimentos entre os atores envolvidos. Sobre essas ações, cf. Cury, (2016b). linguagens, representações, vocalidades e visões podem estar em um mesmo museu, com destaque à participação indígena, em outras palavras, introduzir a descolonização como mais uma opção no museu.

Dentro das discussões atuais sobre descolonização e indigenização dos museus, para citar duas linhas que podem se associar, há os processos colaborativos ${ }^{15}$ que vêm se realizando desde os anos de 1970 nos museus. Pela colaboração, ações museais são geradas perpassando toda a curadoria, aqui entendida como todas as ações em torno do objeto - coleta/formação de coleções, pesquisa/estudo de coleção, salvaguarda e comunicação - todas elas participam e/ou são afetadas pela colaboração. Em decorrência do caráter experimental, a colaboração envolve conceitos, metodologias, técnicas e tecnologias ainda em construção, por isso a profusão de termos, tais como cooperação, participação, colaboração, etnomuseologia, museologia colaborativa, museologia social, museologia compartilhada, curadoria compartilhada, repatriamento virtual e redes virtuais, como também inclusão, ação política, diálogo, interculturalidade, interatividade, acessibilidade etc., termos reveladores da dinâmica que vivenciamos. ${ }^{16}$

Na conjuntura atual, o mínimo que o museu etnográfico deve fazer, indo além da curadoria, é informar os povos indígenas acerca do que detém sob sua guarda, pois é um direito desses povos saber onde estão os objetos de seus antepassados. ${ }^{17}$ Nessa linha, deve criar os acessos às coleções para os indígenas, criando as condições para que estejam com os objetos presencialmente, ou acesso virtual, quando o encontro não for possível. Ainda, dar a devolutiva sobre as pesquisas de campo realizadas nas aldeias indígenas e prestar contas de como 0 museu salvaguardou os objetos. Não raramente, os indígenas são pegos de surpresa quando informados sobre objetos de seus povos em dado museu. Quando sabem sobre a coleta e entrada institucional, desconhecem o destino museal. Frequentemente reclamam da falta de retorno sobre os resultados das pesquisas, mas não se esquecem que um dia receberam um pesquisador. Também comentam que para levar (o objeto, a informação) foi fácil, dar retorno (das pesquisas, sobre a guarda do objeto) é difícil. O pesquisador, por sua vez, justifica-se pelos prazos e recursos limitados. A situação é de difícil solução, mas o museu precisa achar formas de acessos e retornos, mas as políticas públicas deveriam sustentar tais processos complexos de curto, médio e longo prazo, a depender de contextos.

A colaboração traz novas frentes como a curadoria compartilhada de coleções e/ou exposições, a (re)qualificação de coleções e a autorrepresentação, entre outras possibilidades.

A experiência que envolve este artigo refere-se a projeto de curadoria com indígenas iniciado em outubro de $2016,{ }^{18}$ com participação integrada das diversas 
áreas do museu, como museologia, educação, expografia, conservação, documentação e arqueologia. Em síntese, o projeto tem a intenção de inserir no MAE-USP, onde se realiza, práticas construídas com a curadoria indígena.

$\bigcirc$ trabalho se realiza com indígenas no Oeste e Centro-oeste de São Paulo, Kaingang das Terras Indígenas (TI) Icatu (Braúna) e Vanuíre (Arco-ĺris), Guarani Nhandewa da Aldeia Nimuendaju, TI Araribá (Avaí), Terena da Aldeia Ekeruá, TI Araribá e TI lcatu.

As coleções desses grupos e nessas regiões e localidades se formaram no fim do séc. XIX e início do XX (Kaingang), pela Comissão Geográfica e Geológica do Estado de São Paulo (CGGESP) e outros coletores, e 1947 (Kaingang, Guarani Nhandewa e Terena) por Herbert Baldus, Harald Schultz e Egon Schaden. Outras peças deram entrada isoladamente também, o que foi considerado.

$\bigcirc$ processo colaborativo com esses grupos foi iniciado com objetivos mútuos entre o MAE-USP: 19

- dar acesso aos indígenas dos objetos de seus antepassados / conhecer os objetos dos antepassados;

- dar retorno sobre as coleções e pesquisas / saber o que aconteceu com os objetos;

- (re)significar as coleções / trazer os objetos para a atualidade, interligando passado-presente-futuro;

- apoiar o fortalecimento cultural / fortalecer as tradições e gerações;

- gerar no museu o protagonismo indígena / apropriar-se do museu;

- tornar o museu um espaço participativo / exercer a autorrepresentação;

- desenvolver novas formas de pesquisa / pesquisar com os mais antigos;

- exercitar a curadoria / ser pesquisador e curador.

A estratégia de atuação se apoiou na exposição Resistência já! Fortalecimento e união das culturas indígenas - Kaingang, Guarani Nhandewa e Terena veiculada na sede do MAE, ${ }^{20}$ no campus Butantã da USP, posto que os indígenas viram nesse lugar uma possibilidade política de visibilidade, querem ser vistos e considerados pelo Brasil, estado de São Paulo e pelos municípios onde residem.

A estratégia de comunicação museológica, que envolve a exposição e a ação de educação de forma integrada, sustentou um processo contínuo de elaboração, atendendo ao interesse dos grupos de se fazerem visíveis, ou seja, de comunicar, posto que: "[...] the greatest strength of a collection lay in its mobility. In other words: in the intentional act of switching the position of exhibits back and forth from analysis and interpretation to public visibility". ${ }^{21}$
19. Sobre o processo e exposição, cf. Cury (2019a).

20. Título definido pelo coletivo indígena. Ocorreram três aberturas em 2019, uma para cada módulo da exposição, correspondente a cada grupo: 15 de março (Kaingang), 10 de maio (Guarani Nhandewa) e 28 de junho (Terena). Essa foi a estratégia de valorização de cada grupo, como também oportunidade para que cada um realizasse seus rituais de autorização e liberação do espaço. Fechada devido à pandemia do coronavirus, a exposição será reaberta quando for autorizada.

21. Ponto de vista de Carl Einstein, teórico alemão da arte africana, contemporâneo de Walter Benjamin e Aby Warburg, mencionado por Deliss (2015, p. 25). 
propósito do artigo é apresentar parte de um trabalho colaborativo que teve um processo expográfico como estratégica central. Os grupos envolvidos participaram ativamente de todo o processo de curadoria, que compreendeu os estudos das coleções (aqui tratado como requalificação das coleções) e elaboração das narrativas expositivas, a partir da seleção dos objetos e escolhas de elementos de comunicação, em consonância com os objetivos dos grupos com a exposição.

Uma parcela do trabalho a que se refere o artigo é o levantamento das coleções no sistema de documentação do MAE-USP, recorrendo aos documentos oriundos do Museu Paulista, instituição que incorporou tais coleções ao seu acervo. A ideia de "trajetória documental" baseou-se em acompanhar cada objeto nos sucessivos procedimentos documentais que alteraram as informações registradas e as possibilidades de localização das peças das coleções. Todo esse processo é integrado ao projeto colaborativo, como uma obrigação da instituição de dar retorno sobre o que o museu fez com as coleções e com cada objeto retirado do passado dos seus contextos de produção e uso, pelos coletores mencionados. Para responder a tal indagação, foram necessárias informações, muitas delas vêm da documentação existente, para isso também elas se justificam no presente. $\bigcirc$ retorno a que nos referimos é institucional, mas é também em nome dos coletores que atuarem em outras épocas e sob outras orientações antropológicas, por isso eles têm atenção na parte inicial do artigo.

Com os dados obtidos (nem sempre elucidativos), os grupos culturais passaram à requalificação das coleções. Cabe esclarecer, muitas das dúvidas do museu foram esclarecidas pelos indígenas nessa outra etapa do projeto colaborativo (participação em todas as etapas).

Como metodologia para se chegar às informações e aos objetos, partimos das fontes de informação mais antigas para as mais recentes. As edições da Revista do Museu Paulista foram consultadas e citadas como fontes, também para a sua valorização, no que se refere às coleções e seus coletores. Mas, a opção pelo periódico também foi devido a ser um registro de gestões e de estatutos conceituais assumidos, e aqui nos interessa particularmente as políticas de gestão das coleções etnográficas e a área de etnologia como receptora de coleções dessa tipologia. 
22. Baldus, (1949, p. 169). O artigo Revista do Museu Paulista foi republicação "D' "O Estado de S. Paulo", 17 de abril de 1948". Disponível pela Biblioteca Digital Curt Nimuendaju, Coleção Nicolai: <www.etnolinguistica.org $>$.

23. Sobre esse processo, Darcy Ribeiro (1988) dedica o capítulo Os Kaingáng e a expansão dos cafezais na obra Os índios e a civilização: a integração das populações indígenas no Brasil moderno. Também, Luiz Bueno Horta Barbosa (2019) A pacificação dos Kaingangs paulistas.

24. "Desde 1922 o Museu publica os Anais do Museu Paulista, que a partir de 1993 passaram a circular em nova série, com o subtítulo História e Cultura Material." <http://www. mp.usp.br/publicacoes/ anais-do-museu-paulista $>$. Acesso: 23/06/20.

25. Bittencourt (2012). A autora apresenta a trajetória da Revista do Museu Paulista na relação com as gestões de diretoria e os estatutos conceituais que o museu adquiriu no transcurso do periódico.

26. Bittencourt (2012, p. 152).

27. Bittencourt (2012, p. 161).
Percebe-se, assim que a periodicidade de apresentação dos exemplares ao público variou; em média temos uma edição a cada dois anos - quando isto não acontecia, os editores 
28. Bittencourt (2012, p. 160).

29. Baldus (1949, p. 170).

30. Françozo, (2005, p. 590591). A autora no artigo $O$ Museu Paulista e a bistória da antropologia no Brasil entre 1946 e 1956 dá destaque à Revista do Museu Paulista e ao Baldus como organizador do periódico, mas também como articulista entre instituições paulistas e internacionais.

31. Baldus (1948, p. 305). O primeiro número da nova série da RMP foi publicado em 1947, mas somente no número 2 (1948) temos o primeiro Relatório da Secção de Etnologia "dirigido ao exmo. Snr. Dr. Sérgio Buarque de Holanda, D. D. Diretor do Museu Paulista" (p. 305). O relatório organiza-se, basicamente, com uma introdução e os tópicos Viagens, Representações, Publicações, Funcionários, Compras, Permutas e Doações Recebidas.

32. Baldus (1948, p. 305).

33. Baldus (1949, p. 170).

34. Baldus (1948, p. 306).

35. Baldus (1949, p. 171). cuidavam de justificar o intervalo entre as publicações o que contribui para a hipótese de que a bianualidade fosse a expectativa para a circulação dos volumes, ainda que tivéssemos uma edição em 1897 e outra em 1898 e, com a chegada de Taunay à direção, um esforço para diminuir os intervalos de publicação com uma sequência anual de volumes para 1918, 1919 e 1920; 1926 e 1927; 1931 e 1932.28

Há uma interrupção da Revista do Museu Paulista em 1938 e na terceira gestão de diretoria (1946-1956), de Sergio Buarque de Holanda (1902 - 1982), o periódico volta a ser publicado (1947-1987). Nos anos da gestão, duas seções do museu passam a ter atenção, história e etnologia. "Talvez a expressão mais clara da sua tendência seja o ardor com que, desde sua nomeação para diretor do Museu Paulista, em 1946, tratou da criação duma Secção de Ełnologia", ${ }^{29}$ compreendendo as coleções etnográficas e arqueológicas. "Naquele período, a coleção de etnografia da instituição encontrava-se abandonada, suas peças não organizadas ou catalogadas, e algumas delas já estavam inutilizadas. Assim, fazia-se necessária a contratação de um funcionário para a organização de tal coleção". ${ }^{30}$ No mesmo ano foi contratado Herbert Baldus (1899-1970), em 20/10/1946 pelo Governo do Estado de São Paulo para as "funções de Técnico de Etnografia no Museu Paulista". ${ }^{31}$ Foi nomeado para chefiar a seção em 1947, "[...] entregue a minha chefia desde que fui nomeado para o cargo de etnólogo, a 4 de janeiro de 1947", 32 mesmo dia em que o Assistente de Etnologia Harald Schultz (1909-1965) foi contratado para organizar e ampliar as coleções indígenas. A Revista do Museu Paulista é retomada, "[...] veneranda publicação tão brilhantemente dirigida por Hermann von thering e Afonso D'Escragnolle Taunay. Era, portanto, preciso conservar um nome já consagrado dos etnólogos. Por outro lado, convinha criar sob êsse nome uma nova série [... $]^{\prime 33}$ para reafirmar o novo caráter dado pela Seção de Etnologia ao periódico, com um perfil etnológico.

Foi reiniciada a publicação da "Revista do Museu Paulista" que, em uma nova fase, funciona como órgão da Secção de Etnologia. O volume correspondente ao ano de 1947 contém estudos de Etnologia, Etno-Psicologia, Antropologia-Física, Arqueologia, Folclore e Linguística. Entre os colaboradores figuram cientistas de reconhecido valor como Max Schmidt, C. H. Goeje, Emilio Willems, Donald Pierson, Egon Schaden, Aniela Ginsberg, Francisco A. Bayerlein, Ettore Biocca, Afonso Hoge, Giorgio Schreiber, Carlos Borges Schmidt, Carlos Borges Teixeira, Silveira Bueno e J. Philipson. ${ }^{34}$

A Revista do Museu Paulista Nova Série (RMPNS) teve as parcerias da Escola Livre de Sociologia e Política (criada em 1933) e da Faculdade de Filosofia, Ciências e Letras da USP (1934), ${ }^{35}$ fato do registro advém dos esforços do antropólogo em 
estabelecer parcerias para benefícios do museu e da antropologia em São Paulo, ${ }^{36}$ interligadas a sociologia e a antropologia e realizadas trocas entre as três instituições, principalmente entre o Museu Paulista e a Escola Livre de Sociologia e Política, pois Baldus servia a ambas, ${ }^{37}$ "além de ter sido o articulador da antropologia brasileira no cenário da antropologia internacional, Herbert Baldus foi também o elo entre o Museu Paulista e os dois outros centros de pesquisa e formação em antropologia em São Paulo nas décadas de 1940 e 1950" o que colocava o Museu Paulista em destaque. ${ }^{38}$ Em substituição na diretoria, em virtude de viagem à Europa de Buarque de Holanda, Baldus estabelece intensa troca de correspondência com antropólogos e museus internacionais, o que favoreceu também a RMPNS. Vários autores internacionais que se dedicavam à etnologia brasileira tiveram seus artigos traduzidos por Baldus ou Schaden e publicados. ${ }^{39}$

Muitos convites surtiram efeito, pois, de fato, pode-se encontrar uma série de artigos desses correspondentes de Baldus em diversos números da nova série da Revista do Museu Paulista. Os nomes que mais comumente aparecem são os de Max Schmidt, Ettore Biocca, Franz Caspar, Fritz Krause e Stig Ryden. ${ }^{40}$

Esse momento do Museu Paulista e da nova série da sua revista nos interessa, em termos da importância que a antropologia teve nessa gestão, mas também a liderança ocupada pela Seção de Etnologia, por isso os relatórios, embora sucintos, da nova Seção se destacam, com descrições sobre intercâmbios internacionais, entradas e permutas de objetos, mas também sobre contratação de pessoal para a etnologia, como Vilma Chiara (1927-2020),41 Thekla Hartmann, Sônia T. Ferraro Dorta, Nobue Miyazaki e Antônio Sergio A. Dammy e outros colaboradores. ${ }^{42}$ Posteriormente, em 1963 o MP é incorporado à USP.

Para atingir os propósitos de traçar as trajetórias de objetos e coleções, seguimos a estratégia inicial de consulta aos relatórios do MP-USP como registros de época na Revista do Museu Paulista sobre entrada e permutas de objetos, mas, a consulta a outros documentos foram essenciais, como vimos a descrever e analisar. A atenção recai sobre os Kaingang, Guarani Nhandewa e Terena em São Paulo, grupos que integram ações de colaboração com o MAE-USP, que nos incitaram a tal levantamento.
36. Françozo (2005, p. 600601). Outro exemplo de articulação, em 1948 o Serviço de Proteção aos Índios (SPI) apoiou uma exposição organizada pelo Museu Paulista na Semana do Índio, Baldus (1951).

37. Françozo (2005, p. 602).

38. Françozo (2005, p. 602).

39. "A partir de 1947, a publicação passou a veicular quase exclusivamente textos de antropologia. Analisando o conteúdo da revista nesses dois períodos isto é, o primeiro de 1895 a 1938, e o segundo de 1947 a 1956, chega-se dados esclarecedores: no primeiro período, foram publicados no total 228 artigos, dos quais $65 \%$ sobre zoologia, $10 \%$ sobre antropologia, $8 \%$ são biografias, $4 \%$ sobre lingüística, $4 \%$ sobre geologia, $1 \%$ sobre botânica e $1 \%$ sobre arqueologia, sendo $6 \%$ sobre outros assuntos. No segundo período, dos 74 artigos publicados, $74 \%$ são sobre antropologia, $8 \%$ são biografias, $6 \%$ sobre arqueologia, $4 \%$ sobre história, $1 \%$ sobre lingüística e $7 \%$ tratam de outros assuntos. Os artigos de antropologia publicados pela revista formavam um conjunto bem ilustrativo do que se considerava o domínio dessa ciência naquela época. Em boa parte, eram artigos voltados para a etnologia indígena, escritos por etnólogos alemães e traduzidos para o português por Herbert Baldus ou Egon Schaden." Françozo (2005, p. 593).

40. Françozo (2005, p. 597).

41. Atuou no Museu Paulista desde 1949 (Baldus, 1950). Foi contratada como conservadora do Museu Paulista em 31/12/1955, conforme relatório "A nova funcionária dedicou-se com o maior entusiasmo a rever 
e completar os registros, tratar da conservação das coleções e preparar uma exposição que teve aplauso geral" (Baldus, 1956-1958, P. 320). Sobre Chiara, Baldus (1956-1958) registra no relatório de 1957: "A Conservadora de Museu, dona VILMA CHIARA, prosseguiu com a mesma eficiência nos trabalhos de revisão dos registros das coleções, nos de conservação das peças e preparação das exposições, tendo durante êste ano preparado duas novas salas de exposição que despertaram grande intêresse por parte do público" (Baldus, 19561958, p. 323). Faleceu em 6 de agosto de 2020 em Curitiba, PR. Ver perfil bio-bibliográfico da antropóloga em Damy e Hartmann (1986, p. 251-250).

42. O artigo trata das coleções etnográficas, por isso questões relativas à arqueologia não são relatadas. No entanto, algumas citações são possíveis sobre coleções arqueológicas, como aquelas feitas por H. von Ihering na Revista do Museu Paulista (n. 6, 1914): "Dentre as acquisições realizadas merece menção em primeiro lugar a rica collecção de objetos pré-historicos do Rio Grande do Sul, organizada pelo falecido escriptor Carlos von Koseritz (p. 5). Na mesma edição está em seguida: "O Museu Paulista em 1901 e 1902", item 2. Collecções e Galerias artisticas, Comprou-se "A Exma. Snra. D. Zeferina von Koseritz, Porto Alegre, Rio Grande do Sul, a riquíssima collecção de objetos arqueológicos do Rio Grande do Sul, organizada pelo fallecido escriptor Carlos von Koseritz" (p. 17). No Guia pelas collecções do Museu Paulista (1907, s.p.), na planta de distribuição das seções, a Sala B12 Anthropologia, Ethnographia (Indios do Brazil) estão quatro armários (53 a 56), um deles destinado à "Archeologia"

\section{AS COLEÇÕES E SEUS REGISTROS}

Quando falamos em levantamento, não buscamos unicamente uma listagem de objetos museológicos. Na listagem final temos os objetos localizados na documentação e na reserva técnica. Mas, em se tratando da complexidade tratada, outras informações são construídas, inclusive sobre os objetos não localizados, a considerar também os motivos, pois a trajetória dos objetos deve demonstrar os problemas de percurso encontrados. Por isso trabalhamos com a ideia de trajetória de cada objeto, para localizar os objetos, mas também para identificar os nós de problemas de percursos. Identificar aquilo que não foi achado é tão importante quanto localizar os objetos.

$\bigcirc$ estudo de curadoria na documentação do MAE-USP envolveu coleções e antropólogos - Curt Nimuendaju43 (1883-1945), Herbert Baldus44 (1 899-1970), Harald Schultz"45 (1 909-1966) e Egon Schaden46 (1 91 3-1991).

Curt Nimuendaju, alemão de origem, chegou ao Brasil em 1903, foi contratado pelo Museu Paulista e, em expedição, levantou dados para o mapa da ocupação indígena no sul do Brasil, publicado em 1911 na Revista do Museu Paulista como "Mappa da actual distribuição dos índios no Brazil meridional", 47 ilustração do artigo de Hermann von lhering A questão dos índios no Brazil. ${ }^{48}$ Há controvérsia sobre a autoria do mapa (Figura 1), uma vez que o artigo é assinado por thering. Ao pé do mapa publicado consta "Organizado por $\mathrm{H}$. von Ihering". $\mathrm{Na}$ Biblioteca Digital Curt Nimuendaju, Eduardo Ribeiro nos ajuda com o levantamento feito para elucidar a questão, ${ }^{49}$ como segue. No mesmo artigo, Ihering ${ }^{50}$ cita:

De especial auxilio me foi o Snr. Kurt Unckel, amigo enthusiasta e bom conhecedor dos indios, a quem muito agradeço o me ter desenhado o presente mappa. Da sua expedição em serviço do Museu no anno passado, e para o sudoeste do Estado de S. Paulo, provieram novas e importantes informações, que vieram corrigir em parte as anteriores.

Na pesquisa de Eduardo Ribeiro temos trechos de correspondências de C. Numuendaju afirmando a sua autoria. A primeira correspondência foi enviada a Guérios em 1944:

No Mapa Ethnographico annexo ao seu trabalho A questão de [sic] indios no Brazil de von lhering acham-se os limites do antigo territorio dos Otí e os logares onde encontrei os ultimos remanescentes. - Este mapa, aliás, não foi "organizado por H. v. Ihering", como reza o titulo, mas exclusivamente por mim. 
Em outra correspondência trocada com Aryon Rodrigues em 1945, Nimuendaju reforça:

O habitat dos Op(h)ayé, tanto no tempo de sua maior expansão (depois do recuo dos Kayapó Meridionais) como no anno de 1908 em que visitei a tribu pela primeira vez o Snr. pode vêr no mapa que acompanha o trabalho de Hermann von thering sobre os indios do Sul do Brasil, na Revista do Museu Paulista de 1910, si não me engano. Apezar do titulo que da como autor aquelle scientista, o referido mapa é exclusivamente trabalho meu.

fato é, segundo pesquisa de Ribeiro:

Este seria, assim, ao que tudo indica, o primeiro mapa etnográfico de Nimuendajú a ser publicado, marcando o início de sua ampla produção cartográfica que culminaria, pouco antes de sua morte, em seu monumental "Mapa etno-histórico", concluído em 1944 e publicado pelo IBGE em 1981. ${ }^{51}$

Esse mapa (Figura 1), com os créditos devidos, nos interessa sobremaneira, pois nele está a mancha territorial Kaingang entre os rios Aguapeí ou Feio e do Peixe. ${ }^{52}$ Nele também consta, próximo a Jacutinga, região de Bauru, os Guarani e Kaioá, localidade onde Nimuendaju viveu, hoje TI Araribá (Avaí, SP), para a qual ajudou na criação da reserva sob os cuidados do SPI em 1907.53

Nesse início de século, entre 1905-1907, viveu entre os Guarani Apapokuva e foi batizado com o nome Nimuendaju. ${ }^{54}$ Quando se naturalizou brasileiro, substitui seu nome de nascença, Kurt Unkel, por Curt Nimuendaju. Nos dois anos em que viveu com os Apapukuva, ${ }^{55}$ realizou o trabalho etnográfico publicado em 1914 revista alemã Zeitschrift für Ethnologie, tradução publicada no Brasil em 1987 como Os mitos de criação e destruição do mundo como fundamentos da religião dos Apapokuva Guarani. Também tirou algumas fotografias que estão publicadas nesse livro, hoje parte do acervo do Museu do Índio, Funai.

Curt Nimuendaju teve uma brilhante trajetória na antropologia. Após falecer, seu espólio foi depositado no Museu Nacional da Universidade Federal do Rio de Janeiro. ${ }^{56}$

Em 1946 foi criada a "Secção de Etnologia" do MP com Herbert Baldus, dando início a um período destacado às coleções indígenas. Tal momento decorreu da necessidade de se conhecer e documentar as coleções, mas também considerálas cientificamente. No MP:
(Armario 56). Mas no Armario 54 constam peças cerâmicas dos "indios do Marajó". A sala B 16 estava destinada exclusivamente para "Ethnographia dos indios Carajá".

43. Sobre o falecimento de Curt Nimuendaju, cf. Hartmann, Thekla, O enterro de Curt Nimuendaju (1883 1945), Revista do Museu Paulista, N.S., n. 28, p. $187-$ 190, 1981-1982.

44. O antropólogo foi homenageado no Editorial (19681969) na Revista do Museu Paulista N.S., n. 18, p. 7-23. Cf. também Sampaio-Silva, Orlando. Herbert Baldus: Vida e obra - Introdução ao indigenismo de um americanista teutobrasileito. Revista do Museu de Arqueologia e Etnologia, n. 2, p. 91-114, 1992. Também: Becker, H. Herbert Baldus 1899-1970. American Antropologist, v. 74, n. 5, 1972.

45. Foi homenageado por $\mathrm{H}$. Baldus com o obituário Harald Schultz 1909-1966, Revista do Museu Paulista N. S., n. 16, p. 7-20, 1965-1966. Sua trajetória antropológica, expedições e coleções formadas estão aí descritas.

46. Sobre a trajetória do antropólogo, cf. Hartmann, Thekla; Coelho, Vera Penteado. Contribuições em homenagem ao Professor Egon Schaden. São Paulo: Museu Paulista, 1981. Coleção Museu Paulista, Série Ensaios, v. 4. Também, Schaden, Egon. Notas sôbre a vida e a obra de Curt Nimuendajú. Revista de Antropologia, v. 15 e 16, p. 77-89, 1967-1968. Disponível em: Biblioteca Digital Curt Nimuendaju $-<$ ht tps://bit.ly/2MKtOCU>

47. Mappa da actual distribuição dos índios no Brazil meridional - Revista do $\mathrm{Mu}$ seu Paulista, 1911, v. VIII, Est. VII. 
48. Ihering (1911).

49. Cf. "Mappa Ethnographico do Brazil Meridional" e sua autoria (Ribeiro 2012) por Eduardo R. Ribeiro. $<$ https://bit.ly/2LyFbwV>. Acesso em: 26/06/20. Agradeço a Eduardo Ribeiro pelas mensagens trocadas sobre esta questão.

\section{0. (1911, p. 139).}

51. Cf. "Mappa Ethnographico do Brazil Meridional" e sua autoria (Ribeiro 2012) por Eduardo R. Ribeiro. <https://bit.ly/2LyFbwV>. Acesso em: 26/06/20.

52. Alguns Kaingang se referem ao rio como Feio. José da Silva Barbosa de Campos (Zeca) nos esclareceu que, segundo a sua mãe, dona Ena de Campos, é feio porque suas águas eram vermelhas pelo sangue dos Kaingang mortos no passado.

53. Cf. Terra Indigena Araribá em: <https://bit.ly/3s3ojzi>. Acesso em: 30 jun. 2020.

54. Sobre o batismo, cf. Schaden, Egon. Notas sôbre a vida e a obra de Curt Nimuendajú. Revista de Antropologia, v. 15 e 16, p. 77-89, $1967-$ 1968. Disponível em: Biblioteca Digital Curt Nimuendaju - <https://bit.ly/3s28LvD>.

55. Hoje Guarani Nhandewa, vivem na Aldeia Nimuendaju, cujo nome homenageia o antropólogo.

56. No Celin, onde localizamos inúmeros documentos sobre os Kaingang.

57. Damy; Hartmann (1986, p. 221).
Essa situação [inicial] modificou-se gradualmente ao longo dos anos, em parte devido à crescente proficiência dos coletores, mas é apenas na década de 40 que entram na Instituição as primeiras coleções cientificas propriamente ditas, apoiadas no emprego de toda uma sistemática e suporte teórico mais abrangente a complementar a coleção de objetos etnográficos ${ }^{57}$

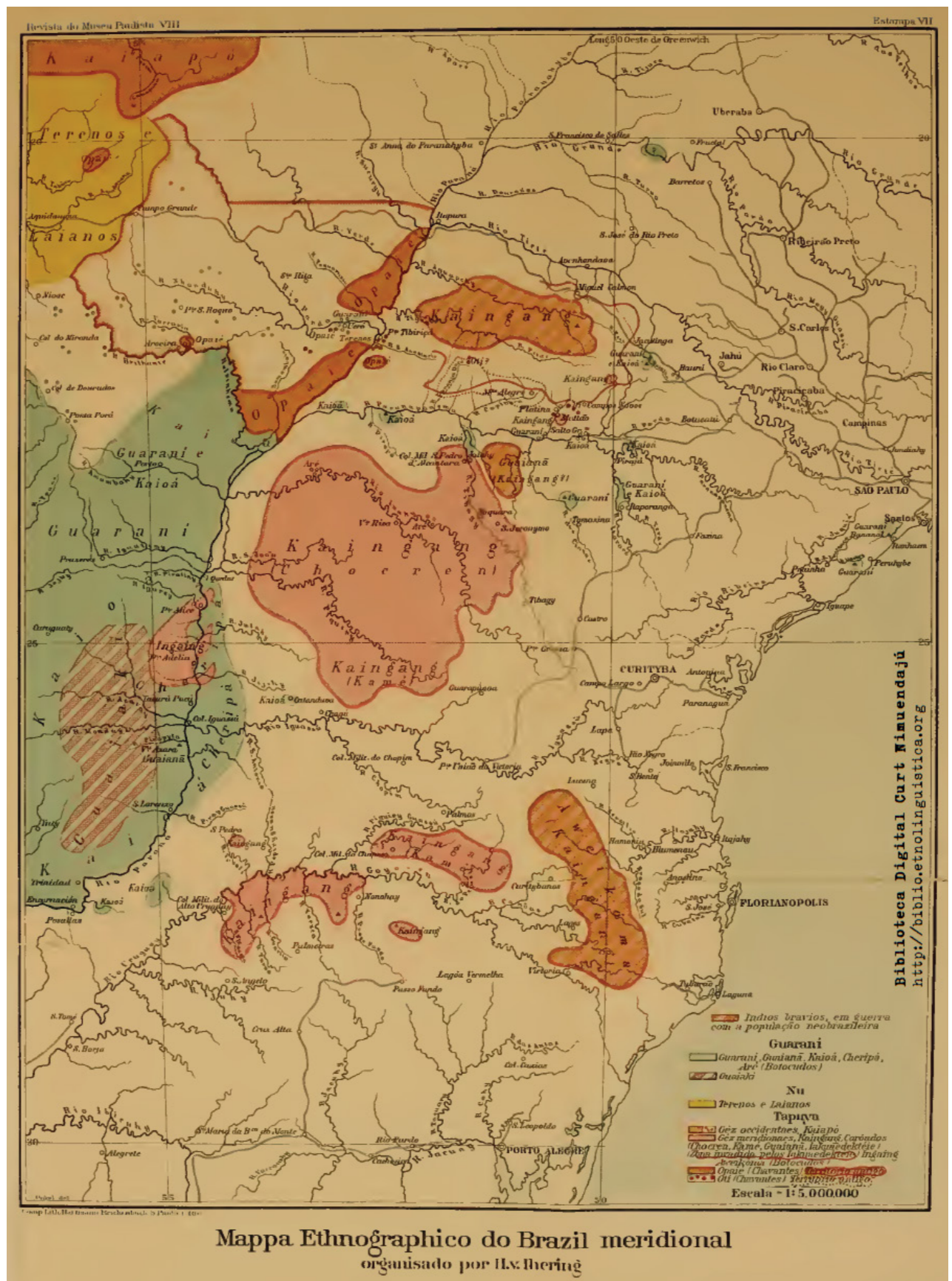

Figura 1 - Mappa Ethnographico do Brazil Meridional. Curt Nimuendaju, 1911 . Fonte: Biblioteca Digital Curt Nimuendaju. 
No MP, Herbert Baldus e Harald Schultz realizaram uma expedição conjuntamente, recém contratados, conforme relatório publicado na Revista do Museu Paulista:

Em fevereiro de 1947 visitei, acompanhado do Sr. Harald Schultz, assistente de Etnologia do Museu, Postos Indígenas instalados pelo Serviço de Proteção aos Índios no Estado de São Paulo, passando do dia 7 a 14 no Posto de lcatu e de 15 a 21 no Posto Curt Nimuendaju (antigo Araribá). Essa excursão foi subvencionada pela Escola Livre de Sociologia e Política de São Paulo e facilitada pelo Serviço de Proteção aos Índios, instituições essas que, desta maneira, iniciaram a sua colaboração com o Museu Paulista. ${ }^{58}$

No "Relatório da Secção de Etnologia" de 1947 publicado na RMPNS, 59 Baldus, além da expedição, faz registro das novas aquisições do MP, entre elas os objetos Kaingang procedentes da TI Icatu, Terena e Guarani Nhandewa da TI Araribá. ${ }^{60}$ Também registra a aquisição de 11 objetos Apapokuva, permutados por Egon Schaden por exemplares da Revista do Museu Paulista. Esse conjunto coletado por Herbert Baldus, Harald Schultz, Egon Schaden e, anteriormente, pela CGGESP e SPI, além de objetos isolados desses grupos e localidades, integraram o projeto que ora apresentamos. Curiosa e lamentavelmente, Harald Schultz, um exímio e dedicado fotógrafo de culturas indígenas, não deixou nenhum registro fotográfico ou fílmico dessa expedição, ${ }^{61}$ exceto os dois retratos tirados na TI Araribá em 1947 de Antonio Lulu (Kaliketé) e de Ladislau (Hahaotí), ambos Terena de lpeque, publicados no artigo Lendas dos índios Tereno de Herbert Baldus. ${ }^{62}$

No MAE-USP a documentação das coleções pertinentes foi levantada nos arquivos do Serviço Técnico de Gerenciamento da Documentação (STGD) ${ }^{63}$ e na Biblioteca. Na Biblioteca foram consultados todos os relatórios antigos publicados nas RMP, na sua maioria organizados por Hermann von lhering, buscando registros de entrada de objetos, como também todos os relatórios da Seção de Etnologia e artigos da equipe do então projeto Coleções etnográficas brasileiras: histórico e composição, coordenação de Thekla Hartmann na década de 1980 e 1990. Nos arquivos do STGD do MAE-USP consultamos todos os inventários, documentos de entrada e demais documentos disponíveis que versassem sobre objetos e coleções Kaingang, Terena e Guarani Nhandewa na região Oeste e Centro-oeste de São Paulo. A partir daí, cada objeto foi buscado na reserva técnica, quando houve a identificação do número de registro, ${ }^{64}$ o que nem sempre aconteceu. $\bigcirc$ fato é, alguns objetos não foram localizados devido a diversos problemas encontrados na documentação - lacunas, contradições, alterações, erros etc., ou seja, uma sucessão de problemas próprios de coleções e instituições seculares, ${ }^{65}$ a serem resolvidos na
58. No tópico Viagens do Relatório, Baldus (1948, p. 306).

59. Baldus (1948).

60. A TI Araribá recebeu diferentes designações, como Posto Curt Nimuendaju.

61. Há a informação de que H. Schultz tivera na região anteriormente, a serviço do SPI. Consta na base de dados do Museu do Índio a informação: Schultz, Harald; Vellozo, Nilo Oliveira Curt Nimuendajú e Icatú Dois Postos Indígenas de Nacionalização. São Paulo: Serviço de Proteção aos Índios. 1942. 1 Filme: película (9 min. $47 \mathrm{seg}$.), SPIVI 009. Disponível em: $<$ https://bit.ly/3bhZWrA>.

62. Baldus (1950).

63. Com apoio da Seção Técnica de Conservação (STC), setores da Divisão de Apoio à Pesquisa e Extensão (Dape) do MAE-USP.

64. Ao contrário da situação da coleção 030 (DeBlasis; Morales, 1997), uma vez identificadas as peças devido a inscrições em cada uma delas, assim como a existência de relação delas, nos estudos curatoriais das coleções dos grupos, não tínhamos uma relação e os números de registros das peças por isso a busca na documentação, algumas vezes em vão. Por outro lado, supomos que muitos objetos ou não foram numerados ou perderam a numeração, pois não foram encontrados. Isso não significa que não estejam no MAE, mas que sem numeração a peça está separada da contextualização.

65. Notamos o mesmo que DeBlasis e Morales (1997) que nos sucessivos inventários foram feitas mudanças de numeração e de informação: "Durante esta transcrição começaram as alterações dos registros." (p. 125). No 
Museu Nacional (UFRJ): "Na segunda metade do século XX o sistema numérico de 1906 continuou em uso pelo Catálogo das Coleções Etnográficas", o que nos informa Veloso (2019, p. 72).

66. Há anos a Dape - Divisão de Apoio à Pesquisa e Extensão do MAE-USP vem realizando o inventário das coleções etnográficas, de modo a reunir todos os sistemas documentais anteriores.

67. Organizado por Marília Xavier Cury, relacionados ao projeto Resistência já! Fortalecimento e união das culturas indígenas - Kaingang, Guarani Nhandewa e Terena, MAE-USP, 2018-2020.

68. Trata-se de carta datilografada de encaminhamento de 11 peças ao Museu Paulista, solicitando em troca o recebimento de números da Revista do Museu Paulista. Assinada por Egon Schaden e endereçada à Herbert Baldus. Uma versão do documento refere-se ao MAE 00485 com "De acôrdo" assinado pelo Baldus.

69. Essa inscrição manuscrita no documento indica um esforço posterior de organização da coleção. No entanto, não sabemos de quem foi a anotação e em que momento, informações que poderiam ajudar a compor a "estratigrafia" na documentação das coleções etnográficas do MP.

70. No relatório, no tópico Permutas, Baldus (1948, p. $308)$, pois no encaminhamento Schaden sugere permuta com a Revista do $\mathrm{Mu}$ seu Paulista.

71. Trata-se de conjunto de documentos. Uma parte do conjunto, sem data, compreende 10 folhas datilografadas com data de entrada e "número de ordem do objeto, que individualiza em relação à coleção". Encontram-se relações de pe- atualidade. ${ }^{66} \mathrm{E}$ para isso este projeto está contribuindo, uma parcela mesmo que pequena de objetos do MAE-USP estará atualizada documentalmente e seus problemas esclarecidos para futuros pesquisadores, evitando retrabalho. Assim, dois Relatórios estão organizados e disponibilizados aos interessados: Guarani Nhandewa e Terena. ${ }^{67} \bigcirc$ relatório sobre os Kaingang está em preparação.

Valem relatos, embora não conclusivos, sobre esse processo de consulta aos relatórios e documental, para reunião das coleções, para demonstrar minimamente o trabalho desafiador em que os museus se encontram.

As coleções Guarani Nhandewa são duas, formadas por Herbert Baldus e Egon Schaden, ambas coletadas na hoje TI Araribá e ingressadas no MP em 1947. Para a coleção Schaden, recorremos ao ofício encaminhado pelo antropólogo datado em 20/05/1947 (doc. 15)68, nele estão relacionadas as 11 peças e, à mão, anotações do Registro Geral (RG) em algumas delas. ${ }^{69}$ Essas informações são confirmadas no Relatório da Seção de Etnologia do MP70 e no doc. 8. ${ }^{71}$ Cruzando as anotações manuscritas do doc. 15 com as fichas catalográficas disponíveis e o levantamento de todas as coleções Guarani do MP,72 foi possível localizar 6 objetos.

A coleção Baldus deu entrada por meio de ofícios com as datas: 6, 19 e 23 de maio e 20 de agosto de 1947 (doc. 167\%3, compreendendo 21 objetos e "sementes para chocalho", quantidade que se confirma no Relatório da Seção de 1947.74 No doc. $8^{75}$ localizamos 20 peças. No doc. 16 há anotações manuscritas posteriores com alguns RG adiante do item. Por meio dessa anotação e levantamento feito por Damy (1983-1984) e fichas catalográficas, chegou-se a uma relação de 14 objetos.

Para a coleção Terena coletada por Herbert Baldus no PI Araribá, hoje Terra Indígena Araribá, foram consultados o documento de entrada (doc. 19) 76 que indica a entrada de 22 objetos no MP. No entanto, no relatório de 1947 publicado, ${ }^{77} \mathrm{H}$. Baldus registrou no item " $C$ " a aquisição de 22 peças entre Kaduveo (4 peças) e Tereno ( 18 peças). As contradições quanto ao total de objetos seguem no doc. 8 e inventários posteriores à entrada da coleção. Para tornar a questão mais difícil, não há fichas catalográficas Terena produzidas no MP. Cruzando-se todos os documentos relativos aos Terena e Kaduveu da época de entrada (1947), chegamos a identificação de 20 peças Terena com seus respectivos RG.

Na oportunidade, localizamos no Livro de Tombo $1914^{78}$ o no. 3309 "Enfeite de pennas de Avestruz - Indios Tereno do Chaco [?]". A informação se repete no Inventário $1916^{79}$ no "Armário A45 - Ethnographia - Indios do Brasil Central", "Enfeites de pennas de avestruz no. 3309". Por outros documentos identificamos o RG444 1 - Saia de pena de ema. Ao localizar a peça na reserva técnica do MAE-USP pelo RG, junto estava a pequena etiqueta 
"B-12 no. 1 Inv 7 p. 134" e outra maior presa por fio "Indios Terena / Sul de Mato Grosso / Saia de pena de emas". No Inventário 7 ( 1932 ) $^{80}$ localizamos a peça, conforme indicação, descrita como "Cintos de penas de avestruz, Terena", repetindo o no. 3309. Naquele que identificamos como Livro Marrom," 81 RG4441 consta como "saia de pena de ema", Tereno. Nesse sentido, a entrada da peça é de ou anterior a 1914, mas contrariamente, no Registro da Secção de Etnologia ${ }^{82}$ consta como "Colecionador Dr. Herbert Baldus". O que se quer trazer para a discussão são as sucessivas inventariações, alterações e os possíveis erros e acertos que podem ter ocorrido, o que exige grande atenção nos levantamentos, como também a manutenção dos números antigos na solução de problemas que encontramos na atualidade. ${ }^{83}$

Também, foram localizados dois abanos Terena (RG1 4065 e RG 14066) incorporados ao MP-USP em 1986 com uma Coleção Rhodia doada pelo Fundo Social de Solidariedade do Estado de São Paulo. Ainda, uma peça cerâmica do espólio de Vera Penteado Coelho doado ao MAE-USP.

As coleções Kaingang têm formação mais antiga. Entre final do século XIX84 até 1947 e itens posteriores com entradas isoladas, muitos objetos Kaingang deram entrada no MP, particularmente coletados durante as expedições aos rios Aguapeí ou Feio e do Peixe pela Comissão Geográfica e Geológica do Estado de São Paulo (CGGESP) nos anos de 1905 e 1907. Sobre as doações da CGGESP, von Ihering em "O Museu Paulista nos annos de 1903 a 1905 (1907, p. 1-30) registra:

A collecções [...] Foi montado apenas um armário novo, com peças ethnographicas dos indios Corôados ou Caingangs, do Oeste de São Paulo, material raro que o museu déve á Commissão Geographica do Estado, que o coligiv em suas explorações do sertão desconhecido, no Oeste do Estado de São Paulo. ${ }^{85}$

No mesmo relatório, o diretor apresenta em "Offertas feitas ao Museu" as doações da CGGESP (p. 19): "[...] varias amostras de mineraes, bem como artefactos indigenas, obtidos pelos Snrs. engenheiros em expedição [...]". A Comissão segue com suas doações de objetos Kaingang em 1906 e 1907.86 Informação interessante na RMP de 1911 sobre participação do Museu na Exposição Nacional do Rio de Janeiro, em 1908, sendo expostos objetos do estado de São Paulo "Cayuás, Corôados ou Caingang e Chavantes, 87 o que conferiu ao MP o Grande Prêmio pela "Commissão Superior do Jury".

$\bigcirc$ conjunto de doações da CGGESP é significativo, pois remete ao doloroso processo de "pacificação" dos Kaingang em São Paulo, o aldeamento ças, respeitando-se a grafia utilizada à época: Umutina, Guarani, Tereno, Kaduveo, Kayuá, Kaingang, Kamaiurá, Uaurá, Mehinako, Kayapó, Parecis, Apapokuva. Em destaque estão os grupos ora tratados, mas considerado também o Kaduveo, pelo cruzamento de peças Terena, como consta no relatório sobre a organização da coleção desse povo no MP. A consulta ao Doc. 8 teve uma eficiência relativa, pela falta de detalhamento. Mas alguns dados se confirmaram. A permuta realizada por Egon Schaden em 1947, permitindo a entrada de 11 peças Guarani do PI Nimuendaju estava demarcada à mão, sem identificação alguma do agente e data, os números de ordem de objeto compreende o 156 a 166.

72. Damy (1983-1984).

73. Trata-se de relação e valores de peças Kaingang, Apapokuva e Caduveu em processo de compra pelo Museu Paulista de Kurt Franck ocorrido entre maio e agosto de 1947. Contem a relação datilografada a partir de manuscritos também presentes nessa documentação. Nos 4 manuscritos constam a relação e valores. Em Damy e Hartmann (1986) consta Herbert Baldus como "Coletor" dessa coleção Guarami (p. 227). As 4 folhas datilografadas estão assinadas por Kurt Franck, com visto do Diretor do Museu Paulista (Sergio Buarque de Holanda). Cada folha corresponde a uma compra em datas diferentes, a saber: datado por K. Frank, peças Apapokuva e Caduveu em 6.5.47, com entrada na Secretaria em 13.5.47; datado por Franck, peças Apapokuva em 19.5.47, com entrada em 27.5.47; datado por Franck em 23.5.47, peças Kaingang e Apapokuva, com entrada em 27.5.47; datado por Franck em 20.8.47, peças 
Kaingang, com entrada em 27.8.47.

74. No relatório, tópico Compras, Baldus (1948, p. 307). Sobre isso, no doc. 16 há os valores e dados de aquisição por compra. No entanto, desconhecemos os trâmites em relação à viagem de visita à Icatu e Araribá.

75. As peças Apapokuva, designação usada para a coleção Herbert Baldus nas fichas catalográficas, foram fáceis de localização na lista, apesar da ausência de detalhes, pela denominação. Entretanto foram encontradas 20 peças de 22 , números de ordem de objeto entre 279 e 300 , exceto os itens 294 e 295.

76. Trata-se de relação de peças com quantidade e valores pagos a Fernando Altenfelder Silva, datado em 09 de abril de 1947 e assinado pelo mesmo, com a conta e entrada na Secretaria do Museu Paulista em 02 de maio de 1947. À caneta tinteiro preta está "índios Tereno" com grifo e abaixo assinatura de Vilma 1963 em azul. Na mesma cor, em folha avulsa, um registro manuscrito "O documento junto se refere a uma coleção feita pelo Dr Herbert Baldus entre os Terena. Data: S. Paulo 9/4/1946", com assinatura Vilma Chiara conservador: $28 / 2 / 63$.

77. Baldus (1948, p. 307).

78. Na p. 154 . O documento apresenta a identificação: Livro de Tombo de 1914, Museu Paulista, Acervos: Arqueológicos e Etnográfico. Em outra cópia do material consta "Catálogo I 'Colleção Ethnographica e Anthropologica Carlos von Koseritz' e Catálogo II".

79. Na p. 188. O Inventário 1916 - Inventário do Museu Paulista - Livro I (S. Paulo, 9 de fevereiro de desse povo nas atuais TI Vanuíre ${ }^{88}$ e lcatu ${ }^{89}$ e tantas violações que sofreram para que fossem integrados à sociedade brasileira, mas confirma e delimita também onde viviam os Kaingang ao longo dos rios Aguapeí ou Feio e do Peixe e da Estrada de Ferro Noroeste do Brasil. Para o levantamento desses objetos foram consultadas cópias xerográficas de inventários, a partir de 1914, relatórios antigos (de von thering), correspondências, artigos e fichas catalográficas. Em 1947 Herbert Baldus e Harald Schultz coletam objetos Kaingang na TI Icatu. Para essa coleção, foram consultados os inventários posteriores a esse ano, correspondências, artigos, fichas catalográficas e o documento de entrada (doc. 16).

As permutas interessam ao levantamento. Através dos relatórios publicados nas edições da Revista do Museu Paulista N.S. é possível saber sobre permutas e doações envolvendo objetos Kaingang, como também sobre localização de objetos Kaingang, Guarani Nhandewa e Terena para informar os nossos parceiros no projeto de colaboração. No Livro de Tombo 1914, há anotações posteriores sobre permutas feitas com o Museu de Buenos Aires envolvendo a saída das peças Kaingang. ${ }^{90} \bigcirc$ Doc. 57 trata de troca de correspondência em 1931 entre Martin Doello Jurado e Affonso D'Escragnolle Taunay "Sobre processo de Permuta entre Museu Paulista e o Museo Nacional de História Natural 'Bernardino Rivadavia'". Muito provavelmente trata-se do mesmo processo, cujas anotações posteriores estão no Livro de Tombo 1914, mas será preciso buscar informações complementares, pois Damy e Hartmann não se referem à entrada de objetos dessa procedência em Materiais etnográficos de outras procedências. ${ }^{91}$

No relatório de 1950 publicado no no. 5 da RMPNS, em permutas, consta saída de material do Museu Paulista para o American Museum of Natural History (AMNH), Nova York, "que se encontra na alfândega de Santos". ${ }^{92}$ A tramitação da permuta se conclui em 1951, conforme relatório no no. 6 da RMPNS: "Do American Museum of Natural History de Nova York, em troca de 153 peças Karajá, 58 de Krahó, 18 de Nambikuara, 5 de Tapirapé e 6 Kaingang, tôdas duplicatas, recebemos uma preciosíssima coleção ethnográfica de índios norteamericanos [...]". 93 ○ Documento MAE00493 trata do "Grande conjunto de objetos de diferentes povos". Do povo Kaingang do estado de São Paulo saíram do MP e deram entrada no $\mathrm{AMNH}$ as 6 peças que seguem, também com as informações catalográficas do $\mathrm{AMNH}:{ }^{94}$

- Faixa de casca de árvore, para carregar crianças (RG2576)

Bast band, Catalog No. 40.0/ 6671, Date: Early/Mid 1900s, Dimensions: L: 74 W: 9 H: 8 (in CM), Collector Herbert Baldus and Harald Schultz Tenaz de cozinha RG2573 
Tongs, Catalog No. 40.0/ 6670, Date: Early/Mid 1900s, Dimensions: L: 57 W: 29.5 (in CM), Collector Herbert Baldus and Harald Schultz

- 4 Panelas de cerâmica, pretas RG2553, RG2554, RG2562, RG2568 / respectivamente:

RG2553 - Pottery Vessel, Catalog No. 40.0/ 6673, Date: Early/Mid 1900s, Dimensions: D: 9.5 H: 14 (in CM), Collector Herbert Baldus and Harald Schultz

RG2554 - Pottery Vessel, Catalog No. 40.0/ 6675, Date: Early/Mid 1900s, Dimensions: D: $17 \mathrm{H:} 14.5$ (in CM), Collector Herbert Baldus and Harald Schultz

RG2562 - Pottery Vessel, Catalog No. 40.0/ 6674, Date: Early/Mid 1900s, Dimensions: D: 23 H: 39 (in CM), Collector Herbert Baldus and Harald Schultz

RG2568 - Pottery Jar, Catalog No. 40.0/ 6672, Date: Early/Mid 1900s, Collector Herbert Baldus and Harald Schultz

documento sobre a saída de peças para a permuta revela:

Nota: Com exceção da panela de no. 2554 RG, encontrada em 23-9-1906 pela turma do Rio do Peixe, da Comissão Geográfica e Geológica de São Paulo, o material acima mencionado foi coligido pelo Chefe da Secção de Etnologia do Museu, dr. Herbert Baldus, na região de lcatu, em 1946 [sic].95

Há divergências entre as informações do Documento e aquelas disponíveis pelo $\mathrm{AMNH}$. A base de dados do $\mathrm{AMNH}$ nos informa sobre outra cerâmica Kaingang: Pottery Vessel, Catalog No. 40.0/ 6679, Field No. 85-624, Date: Early/Mid 1900s, Dimensions: D: 21 H: 17,5 (in CM). Sobre essa peça cerâmica, não temos informações a partir do número de origem que seria o Field No. 85624. Além disso, a cerâmica RG2554, Catalog No. 40.0/ 6675, Collector Herbert Baldus and Harald Schultz, foi coletada em 1906 e doada pela CGGESP, cf. Documento MAE00493. Na foto da peça, podemos ver a inscrição inclinada 1152 em tinta branca meio transparente sobre o fundo escuro da cerâmica. Consultando a documentação antiga, ${ }^{96}$ a peça 1152 refere-se à "Panella dos indios Coroados, encontrada pela turma do R. do Peixe em 23 de IX 1906 No. 16", doação da CGGESP. No Inventário 7 (item 129) consta a peça 1152 , sem informações, apenas "Panella Caingang", mas encontra-se no meio de conjunto de peças identificadas como presentes no Livro de Tombo 1914. No Inventário 7
1916): Organizado por Sala, armário e área.

80. "Inventário do material exposto a visitação pública nas diversas salas do Museu Paulista das Secções de Historia e Etnografia", com Termo de Abertura datado em $02 / 12 / 1932$, com a anotação de que teve como base " $[\ldots]$ as notas lançadas nos livros de inventário de 1915-1917", assinado pelo "Director do Museu Paulista Affonso E. Taunay". Chegamos à informação de que este é o Inventário 7, pois no documento não há nenhuma indicação sobre is so. Trata-se de inventário organizado por sala de exposição. Na página 126 inicia-se "Sala B12 de Etnografia - Revisão do Inventário (Dezembro de 1932)". Há, então, a relação numerada de peças por armário com seus respectivos números, quando existentes.

81. Registro Geral da Secção de Etnologia do Museu Paulista, sem data. Encadernação com capa dura de cor marrom, com relação de peças datilografadas na cor azul (cópia de carbono), numerado até a folha 100 , mas com cerca de 200 folhas. No Livro de Capa Marrom estão os objetos relacionados, a começar pelo RG1131 na primeira coluna, a última está destinada a Reg. anterior, mas na maioria da vezes encontra-se em branco. Os descritivos são sucintos (panela, cesto), mas às vezes é possível estabelecer uma relação com os inventários anteriores. Possivelmente década de 1950 . No relatório de 1950 Baldus menciona a finalização do Registro Geral. DeBlasis; Morales (1997, p. 125) mencionam a separação da documentação e numeração das coleções etnográficias e arqueológicas em 1958.

82. O Registro da Secção de Etnologia é cópia xerox do original (como os demais in- 
ventários), sem termo de abertura, sem data. Trata-se de conjunto de 15 volumes, com folhas de tamanho aproximado A3 $(29,7 \mathrm{~cm} \mathrm{X} 42 \mathrm{~cm})$ presas por espiral. Os cadernos contém as colunas Observação; No. Anterior; Local de Depósito; Data (Coleta e Entrada); Colecionador; Grupo Étnico; Objeto; R. Geral [Registro Geral].

83. DeBlasis e Morales (1997) comentam os prejuízos que as sucessivas catalogações trouxeram, ao trabalhar com a Coleção 030. Comentam também os quatro números encontrados nas peças da coleção, o que, lamentavelmente, não ocorre nas peças etnográficas como esta Terena e muitas outras Kaingang. Também, nem sempre conseguimos emparelhar todos os números atribuídos desde 1914.

84. Nos faltam informações sobre a coleção do Major Sertorio e da identificada como Coleção Antiga, que antecedem a criação do Museu Paulista.

85. Ihering (1907, p. 6).

86. Ihering, (1911, p. 11, 19, 20).

87. Ihering (1911, p. 6).

88. Tornada Reserva Indígena do SPI em 31/12/1917. Ver: <https://bit.ly/3nqhdRK>.

89. Tornada Reserva Indígena do SPI em 31/12/1919. Ver: <https://bit.ly/399RFDu>.

90. Nos. 5109, 5112, 5117, 5120, 5134, 5144, 5146-50, (p. 70-73).

91. Damy; Hartmann (1986, p. 247).

92. Baldus (1951, p. 284).

93. Baldus (1952, p. 520). Em Damy; Hartmann (1986, p. ainda se usava uma numeração antiga, o Registro Geral (RG) passa a ser adotado posteriormente. ${ }^{97}$ Este é um exemplo entre tantos outros em que buscamos confirmações e, na comparação entre documentos, encontramos lacunas. ${ }^{98}$ Possivelmente a mudança de numeração para o RG - Registro Geral tenha se dado após 1950, mesmo ano do envio de material para o AMNH em permuta. No relatório desse ano, em "Registro Geral" há a menção: "Foi concluído o Registro Geral, mostrando que a Secção possui um total de 9.584 peças $^{99}[\ldots]$, entre as etnográficas estão "[...] 5.921 peças etnográficas de índios sul-americanos". 100

Pelo relatório de 1952 no no. 7 da RMPNS, em "Viagens", Baldus ${ }^{101}$ nos informa:

g) Dinamarca: No Museu Nacional de Copenhague há um lugar de romaria para os estudiosos das coisas do Brasil: é a sala tupinambá, com objetos dos antigos donos índios do litoral e os célebres quadros de Eckhout do século XVIII. Ao lado há outra sala brasileira onde se vêm peças munduruku, kadivéu, Kainguá, kaingang e apinajé.

Em 1956 o relatório ${ }^{102}$ registra viagem ao exterior entre 18 e 31 de agosto, "a convite do Real Instituto Tropical dêsse país, a fim de colaborar no entabulamento de intercâmbio científico entre essa instituição e o Brasil [...]", ${ }^{103}$ o que resultou em permuta com a instituição de Amsterdã. "A 11 de fevereiro tiveram entrada neste Museu [...] coleção de máscaras procedentes 10 da ilha de Java, 1 da itha de Bali e 1 da itha de Nova Guiné [...]". 104 O Documento MAEO0489, com anotação manuscrita 30 de Outubro, 1956 e Vilma [Chiara?]. Conforme documento, em 26/12/56 foram encaminhadas diversas peças por essa permuta, entre elas "panela barro Kaingang 2.569". Damy e Hartmann ${ }^{105}$ confirmam a permuta, indicando a entrada das peças recebidas em 1957.

Thekla Hartmann coordenava o projeto Coleções etnográficas brasileiras: composição e história. O projeto trouxe algumas contribuições. Em artigo Materiais etnográficos brasileiros na Suiça, de Antônio Sérgio Azevedo Damy, estão as seguintes informações: 106

\author{
"Etnia" Chamacoco, Lengua, Guana, Guato, Coroados, Caduveo \\ "Coletor" E. Hassler 1886 \\ "Ano" (entrada na Inst.) \\ "No. Peças" 202
}


No artigo Coleções etnográficas no interior do estado de São Paulo: composição e história, Renata Parada Pazinatto nos revela detalhamento do acervo fotográfico no Museu Universitário da PUC Campinas, a saber: 23 fotos, 1911 , autor Expedito Rabello, Guarani da Aldeia de Araribá. ${ }^{107}$ No Laboratório de Estudos Antropológicos Unesp, Presidente Prudente: Terena, Posto Cachoeirinha, MS, compra da Funai, entrada 1978, vaso (rg 162) e instrumento musical (rg 240). ${ }^{108}$ No mesmo texto, Kaingang PI Vanuíre, coletor N. A. P. Duran (doador), entrada 1973, cerâmica (rg 30). ${ }^{109}$ Ainda, no Museu H. P. Cacique Tibiriça, Pirapozinho: Terena, Miranda, MS, coletor D. B. Oliveita, 1975-1981, 6 peças: cerâmicas, abanos, maracá. ${ }^{10}$

Após a criação do MAE-USP (1989), o projeto dá continuidade e os resultados são, desde então, publicados na Revista do Museu de Arqueologia e Etnologia. Nesse periódico, Klaus-Peter Kastner publica As coleções brasileiras do Museu Estatal de Etnologia de Dresden. No artigo constam as informações: Kaingáng (sub-grupo Bagai), sem localização, coletor H. v. Inhering, 1925, 1 peça, tembetá (No. 40651 1):111 Tereno do Mato Grosso (Calinto), coletor R. Rohde, 1884, 9x3 peças; Tereno Mato Grosso, coletor Th. Schumann, 1910, $17+3$ peças (p. 156). A pesquisadora Leonor Schumann, bolsista do CNPq, com Thekla Hartmann, contribuíram com o artigo Coleções etnográficas brasileiras em Stuttgart: histórico e composição (1992). As pesquisadoras registram:

Kaingang, Bauru, Est, de São Paulo, coletor G. Konigswald, ano 1903-1905 (?), 1 peça Cesto Cargueiro de bambu.

Kaingang (Coroado), Paraná, coletor G. Konigswald, ano 1903-1905 (?), 64 peças: armas, adornos, ítens do cerimonial, instrumentos musicais, cestaria. ${ }^{112}$

Todas essas informações sobre objetos Kaingang, Guarani Nhandewa e Terena em outros museus além do MAE-USP, que tem a guarda atual, são muito importante para os grupos envolvidos, apesar de ser um levantamento restrito aos periódicos implicados, a Revista do Museu Paulista e a Revista do Museu de Arqueologia e Etnologia.

conjunto de objetos Kaingang ainda está em processo de organização, dada a enorme quantidade, antiguidade e complexidade do conjunto ${ }^{113}$ e sucessivas mudanças de numeração por diferentes gestões documentais do MP, o que nos leva, ainda, a cruzar todos os documentos para traçar o percurso de cada objeto.
247) a coleção norte americana com 172 objetos deu entrada em 1955. De acordo com documento, Exchange with Museu Paulista, São Paulo Brasil - North American Indian Ethnological Collection - Objetos recebidos por regiões e grupos (quando há a informação), conforme documento: Plains Indians. Indians of the Southwest (Apache, Hopi, Mescalero, Mescalero Apache, Mishongnovi, Navajo, Papago, Pima, Pueblo, Taos, Zuni). Southwest Pottary (Hopi, Navajo, Santa Clara, Santa Domingo, Sia, Tesuque, Yuma, Zuni). Indians of the Northwest Coast (probably Bella Bella, Haida probably Kwakiutl, Ojibway, probably Tlingit, Tlingit, probably Tsimshian). Indians of the Eastteastern Woodlands (Chitimacha, Iroquois, Ojibway, probably Winnebago). Indians of California.

94. Informações encontradas na base de dados, South American Ethnographic Collection, pesquisadas e cedidas por Ana Carolina Delgado Vieira, conservadora no MAE-USP, em 14 de agosto de 2018 por e-mail.

95. Documento MAE00493. Supomos que ocorreu um erro de data, pois Baldus e Schultz estiveram na TI Icatu no início de 1947 , apesar de que ambos estiveram com os Kaingang de Ivaí (PR) em 1946, de acordo com Damy; Hartmann (1986, p. 230), antes da entrada deles no $\mathrm{Mu}$ seu Paulista em 1946 e 1947 respectivamente.

96. Livro de Tombo (1914, p. 36-37).

97. Segundo DeBlasis e Morales (1997), a documentação das coleções etnográficas e arqueológicas têm separação definitiva em 1958 (p. 125), com a adoção do RG (Registro Geral) e RGA (Registro Geral de Arqueologia). No Museu Nacional (UFRJ), é de 
1906 o Catálogo Geral das Coleções de Antropologia e Etnografia que reunia as coleções antropológicas (crânios, esqueletos e ossos), etnográficas (de povos indígenas do Brasil e de outras partes do mundo) e arqueológicas (do Brasil e da América). Em 1943 as peças de antropologia física recebem um catálogo específico, nas décadas seguintes o mesmo ocorre com as coleções arqueológicas.

98. "Durante esta transcrição começaram as alterações dos registros. De fato, ao se observar os diversos documentos produzidos ao longo das várias catalogações e triagens realizadas no acervo do Museu Paulista ao longo dos anos, percebe-se uma contínua perda ou descaracterização das informações do livro de tombo original (1914), provocada por constantes erros ou descuidos na transcrição das informações, acrescidas de abreviações ou supressões intencionais no texto original em cada nova descrição da peça. Tal procedimento foi acarretando, ao longo do tempo, uma enorme redução no teor da informação disponível acerca das peças [...]". DeBlasis; Morales (1997, p. 125).

99. Também relacionadas: 196 peças etnográficas de indios sul-americanos, 96 peças etnográficas afro-brasileiras, 3.371 pelas arqueológicas americanas.

100. Baldus (1951, p. 284).

101. Baldus (1953, p. 423).

102. Baldus (1959). Entre os números 1 (1947) e o 11 (1959) os relatórios da Seção de Etnologia estavam no fim da publicação como um texto único. A partir do número 12 (1960), informações da Seção estão em "Notícias do Museu Paulista".

103. Baldus (1959, p. 318).
Para uma tentativa de localização dos objetos Kaingang, foi organizada uma planilha para, por diversos meios como numerações (foram vários os números atribuídos até chegar ao RG), denominações e descrições ${ }^{114}$ e outras, traçar um paralelo entre os registros no passado (1914, 1916, Inv. 7 de 1932, Livro Marrom e outros) e no passado recente (Registro da Secção de Etnologia, sem data, e fichas catalográficas). Mas nem sempre é possível, fato principal foi a mudança de numeração, mas também a retirada ou extravio dos números antigos de algumas peças. ${ }^{115}$ Podemos ilustrar as dificuldades e possibilidades de acompanhar as peças pela documentação, com peças de importância etnográfica e histórica, considerando a documentação e as descrições apresentadas:

"Flechas de indios Caingang do Rio Feio". "Offer. pela Comissão Geográfica e Geológica de São Paulo, coll. pela expedição do Rio Feio 1905" (Livro de Tombo 1914, p. 28-29, números 890-893). Encontramos a numeração 890-893 como "Flexa (sic) de indios Caingangs" (Inventário 1916, p. 180). Três das flechas foram registradas separadamente como 891 e 890 - "Flecha (Coroados)" (Inventário 7, item 99 e 105, p. 240), 892 - "Flecha com ponta de ferro (Coroados)" (Inventário 7, item 108, p. 240).

"Curú ou manto dos indios Caingang ou Coroados feito de fibras de ortiga brava" (Livro de Tombo 1914, p. 34-35, no intervalo entre os números 1116 1120 ). No registro, em seguida 1119 "[...] em forma de camisa sem manga [...]". No Inventário 7 (1932, item 107) a peça aparece como "1 119 - Camisa de fibra de urtiga". Pelo número 1119 pudemos localizar o RG3285 - "Camisolão" (Livro Marrom, déc. 1950). Este é um exemplo de possibilidade de acompanhar o percurso da peça, sem perda de informações, pois as modificações foram mínimas.

"Caningangs (sic) - Col Antiga"16 (Livro de Tombo 1914, p. 35, números 4569 e 4570 [?]]. Em seguida, as peças com esses nos. aparecem como "Arco de Caingangas (sic) (Collec. Antiga)" (Inventário 1916, p. 182). Posteriormente (Inventário 7, p. 130, itens 104 e 113) as peças são separadas e designadas como "Arco Coroados".

- "Craneo de indio Coroado 60 annos capitão morto por ocasião do assalto que os indios fizeram a 31 de jutho de 1906 na faa [...] da Corredeira, mun. Baurú _ SP [...] Otto Dreher ${ }^{117}$ leg. XI O6 - [...] documento [...] A7 Archivo" (Livro de Tombo 1914, p. 34-35, números 1110 -1 1111 1). Foi localizado o no. 1110 "Craneo de indio Coroado" (Inventário 1916 Livro 1, Sala B12, Armario A44, Ethnographia do Est de S. Paulo, p. 182). Outro no. 1110 está como "Fibras (cordas) (Coroados)" (1916 - Inventário do Museu Paulista no. 4,118 item 97, p. 240). O no. 1110 está como "Fibras (cordas) Coroados" (Inventário 7, item 97, p. 130). Nesse inventário 
não consta esse remanescente humano Kaingang. De fato, em determinado momento os remanescentes humanos deixam de aparecer nos inventários.

- "Arco de guerra dos indios Coroados encontrada depois do ataque a turma do R. do Peixe 23.IX.06 No. 9 offr da Comissão Geogr e Geologica SP" (Livro de Tombo 1914, p. 36-37, número 1 140). O no. se repete como "Arco (Coroados) (Livro de Tombo 1916, item 100, p. 240 e Inventário 7, item 100, p. 130). Essa peça e outras 26 Kaingang (Coroados) constam do doc. 79/01670, 16/04/1907, correspondência enviada por João P. Barbosa, chefe da CGGESP.

- "Panella dos indios Coroados, encontrada pela turma do R. do Peixe em 23 de IX 1906, No. 16 idem [offr da Comissão Geogr e Geologica SP]" (Livro de Tombo 1914, p. 36-37, número 1 152). Trata-se da cerâmica permutada com o $\mathrm{AMNH}$, RG2554 identificado a partir da numeração de 1914 mantida inscrita na peça.

- "Panella dos Caingang E Garbe leg 1910 Estação Hector Legree Estr. Ferro Noroeste do Brazil" (Livro de Tombo 1914, p. 159, número 3428). Essa peça foi identificada posteriormente como RG2559.

- "Cocron" panella dos Kaingang do rio Feio Tribo de Vauhin. Pacificados a 19 de Março de 1912 offerecido ao Museu pela Inspetoria do Serviço de Proteção aos indios em S Paulo", com acréscimo posterior RG2566, possivelmente letra de Thekla Hartmann. (Livro de Tombo 1914, p. 194-195, número 3891). Essa cerâmica mantém o no., mas como "Panella (Caingang)" (Inventário 1916, item 131 , p. 242; Inventário 7, item 131, p. 1321. O que nos chama a atenção é o registro do nome de Vauhin, um dos inúmeros chefes de grupos Kaingang que habitavam o território e que foram aldeados. A peça é contemporânea à "pacificação".

- "Flecha com ponta de ferro dos índios coroados colhida apois o ataque de Araçatuba estação da Estrada de Ferro Noroeste a uma turma de trabalhadores de roça onde pereceram 6 desses homens esta flecha foi offda a Secr. da Agricult pelo Engenheiro Victor Lima [?] VIII 1915 (Catálogo II - Colleções Anthropologica e Ethnografica INV. 14, p. 242, item 33, número 4502). Noutros inventários (1916, p. 182; 7, item 122, p. 132) "Flexa com ponta de ferro (indios Coroados)". $\bigcirc$ doc. 78 (N. Antigo 4502) consiste em correspondência de 25/08/1915, da Secretaria d'Estado dos Negocios do Interior para o "Snr. Director do Muzeu (sic) Paulista", com o mesmo texto. Nota-se, a ponta de ferro, material adquirido após o contato, assim como a descrição que reforça a publicidade negativa contra os Kaingang em São Paulo.

- "Colar de ossos de ave (Indios Coroados do Rio do Peixe) (Catálogo II - Colleções Anthropologica e Ethnografica INV. 14, p. 72-73, no. 5143). Depois, "Colar de
104. Baldus (1959, p. 322).

105. Damy; Hartmann (1986, p. 247).

106. Damy (1986, p. 215).

107. Pazinatto (1987, p. 273).

108. Pazinatto (1987, p. 286).

109. Pazinatto (1987, p. 287).

110. Pazinatto (1987, p. 289).

111. Kastner (1991, p. 152).

112. Schumann; Hartmann (1992, p. 127).

113. Trazemos para as coleções Kaingang a constatação em DeBlasis; Morales (1997, p. 128): "[...] na verdade, as referências obtidas para a coleção 030 extrapolam o âmbito puramente técnico-científico da documentação museológica. Não pouco da história da mentalidade científica de uma época, e da própria história do Museu Paulista, está nelas (literalmente) inscrita". Os autores, ainda, revelam que há objetos Kaingang na Coleção 030 designados como arqueológicos, mas que são, de fato, etnográficos.

114. Porque tinha os diversos números atribuídos às peças, DeBlasis e Morales lograram o preparo da Tabela 4 "Exemplos de perda de informações nas sucessivas catalogações do acervo arqueológico do Museu Paulista" (1997, p. 126).

115. Nem sempre é possível emparelhar as diversas numerações atribuídas ao longo dos anos para se compor uma trajetória dos objetos até a atribuição do RG, situação contrária a encontrada por DeBlasis e Morales (1997, p. 112) que tinham a coleção reunida e os números nas peças: "Observou-se também em muitas destas peças uma estratigrafia de até quatro registros numéricos diferentes, materiali- 
zando na coleção uma longa história museológica que, muito provavelmente, seria possível resgatar".

116. Sobre essa coleção, DeBlasis e Morales (1997, p. 127): "No caso da coleção formada pelo major Joaquim Sertório, a primeira a integrar o acervo do Museu Paulista, muitas de suas peças estão escamoteadas pela denominação collecção antiga do Museu Paulista ou simplesmente Colecção Antiga. No livro de 1914, as peças 4.546, 4.547 e 4.598 estão registradas como provenientes da Collecção Antiga - Sertório, indicando serem ambas a mesma coisa, ou que a primeira engloba a segunda. Além do mais, no Relatório sobre os trabalhos da secção zoológica durante o ano de 1893, elaborado por von Ihering (em depósito nos arquivos da documentação do MAE), encontram-se alguns comentários sobre a transferência de uma série de "antigas coleções" para o museu recém-construído, isto é, o Museu Paulista, estando aí incluídos tanto materiais etnográficos quanto arqueológicos".

117. Conforme Ihering (1904, p. 4-5), "O Museu Paulista em 1901 e 1902 [...] Em compensação foram corôadas de completo exito as viagens de exploração, feitas por parte do pessoal deste Museu e dos collecionadores seus correspondentes. Dentre as collecções que recebi destes ultimos são dignas de notas as dos Snrs. Ricardo Krone em Igaupe, Wilhem Ehrhardt em Santa Catarina e Otto Dreher em Franca. Este ultimo collecionador transmitiu ao Museu collecções que fez no extremo oeste do Estado em município que até agora não tinha sido explorado".

118. O Livro I tem a data "S. Paulo, 9 de fevereiro de ossos de aves (Caingangs) (Inventário do Museu Paulista no. 4, 1916, p. 242, 126 - n. 5143). O n. 5143, a grafia e a descrição estão semelhantes no Inventário 7 "Collar de ossos de aves Coroados" (1932, item 126).

- "8. Doação da Sra. Nair Ghedini,"19 em 12/06/78, de uma panelinha de barro dos índios Kaingang, oferecida ao Museu Paulista pela índia Candira" (RMPNS, n. 26, 1979). A doação está no doc. 109, sem data. Por meio de ficha catalográfica, chegamos ao RG1 3549 e o ano de 1978. Essa peça é de grande importância para o projeto de colaboração do MAE-USP com os Kaingang, Candire, Maria Cecilia de Campos, era a avó de Zeca Ulosé da Silva Barbosa de Campos), um dos curadores indígenas.

$\bigcirc$ que expomos são alguns, mas importantes, aspectos que enfrentamos ao organizar as antigas coleções de uma instituição de grande alcance quanto a quantidade, representatividade e diversidade indígena. Por isso, julgamos absolutamente válida as questões para reorganização de coleções no MAE-USP:

A primeira delas corresponde aos problemas resultantes da prática de realizar sucessivas triagens e inventários. Neste caso, por exemplo, tal prática resultou, em um período extenso de mais de cem anos, em alterações e perdas significativas na fidelidade das informações originais. Em princípio, alguns procedimentos de rigor nas transcrições, incluindo data e quem as fez, bastariam para evitar, ou ao menos restringir significativamente, essa perda. ${ }^{120}$

enfrentamento passa pela documentação e suas sucessivas camadas constituídas no tempo, como parte da gestão de coleções. Recorremos ao passado, mas no presente precisamos olhar para o futuro da instituição, mas também dos povos indígenas e seus direitos no museu.

\section{REQUALIFICAÇÃO DE EXPOSIÇÃO E SUAS CONTRIBUIÇÕES}

Um entendimento sobre (re)qualificação de coleções precisaria ser realizado, cruzando as iniciativas existentes que envolvem grupos indígenas como curadores na formação e/ou no estudo de coleções formadas no passado. No geral, essas ações são muito bem coordenadas por antropólogos e mais recentemente por museólogos e arqueólogos. Com atenção na instituição, e a depender das circunstâncias, requalificação é um processo contínuo e cumulativo, quando envolver uma mudança institucional, como o caso experimental 
apresentado. Nesse sentido, o Museu do Índio (Funai) é um exemplo a ser mencionado. Esse museu desde 2000 tem na sua política de atuação a qualificação de coleções. Após anos de trabalho, as ações de qualificação de coleções no Museu do Índio alteraram em profundidade não somente a gestão de coleções desse museu, mas a forma como concebem e realizam curadoria, o Programa de Documentação do Patrimônio Cultural dos Povos Indígenas ProgDoc integra formação de coleções, formação de pesquisadores indígenas e não indígenas, gestão documental e exposições. ${ }^{121}$ Um aspecto particular que aproxima o Museu do Índio do MAE-USP é que a qualificação de coleção acontece integradamente a um processo expográfico, o que, no sentido da mudança, faz o museu operar estrategicamente com a participação indígena motivada pela dinâmica comunicacional e pela autorrepresentação.

No MAE, o primeiro contato dos grupos indígenas com os objetos se deu em 2016 com os Kaingang, quando um conjunto de objetos desse povo sob a guarda do MAE-USP foi levado para a região onde vivem, parte da exposição $\bigcirc$ olhar de Hercule Florence sobre o índio no Brasil'122 no Museu Histórico e Pedagógico Índia Vanuíre, Tupã, SP. A qualificação ${ }^{123}$ foi nos meses de abril ${ }^{124} \mathrm{e}$ maio, ${ }^{125}$ com a participação das Terras Indígenas Icatu e Vanuíre. ${ }^{126}$

Os Kaingang, Guarani Nhandewa e Terena que integraram o projeto tiveram acesso às imagens dos objetos e outras obtidas após pesquisa em outras instituições nos primeiros meses de 2017.127 Em julho de 2017 aconteceu à visita ao MAE-USP, para o encontro dos indígenas com os objetos de seus antepassados. Foram três semanas de trabalho, considerando conhecer o museu e a requalificação das coleções. ${ }^{128}$ Executamos uma programação básica para os três grupos: dia 1- viagem e hospedagem; dia 2- recepção com café da manhã coletivo e venda de artesanato, manhã, e trabalho com os objetos, a tarde; dia 3- conservação e restauro, reserva técnica e documentação museológica, manhã, trabalho com os objetos, a tarde; dia 4- exposição e educação, manhã, e trabalho com os objetos, despedida com apresentação cultural, a tarde; dia 5- viagem de retorno. Além da requalificação, quando discutimos sobre os objetos, os envolvidos escolhera as peças que integrariam a exposição Resistência já! Fortalecimento e união das culturas indígenas - Kaingang, Guarani Nhandewa e Terena. ${ }^{29}$

Para os Guarani Nhandewa foram separados os objetos coletados por Schaden e Baldus na TI Araribá, como outros indicados como Nhandewa no artigo O acervo Guarani do Museu Paulista: contribuição para uma classificação sistemática de Sergio Damy ${ }^{130}$ de outras regiões paulistas, uma vez que os envolvidos manifestaram interesse de conhecê-los também. A partir do Documento 18 (oficio e relação encaminhadas por Schaden), separamos outros objetos
1916" e o no. 4 "S. Paulo, 22 de fevereiro de 1916.

119. Então diretora do Museu Histórico e Pedagógico Índia Vanuíre, Tupã, SP.

120. DeBlasis; Morales (1997, p. 129).

121. Couto (2016).

122. $1^{\circ}$ mar. a $1^{\circ}$ maio 2016 , organização do Instituto Hercule Florence.

123. Projeto Requalificação de Coleções, financiamento parcial do CNPq, proc. 44368320158. Suporte logístico e participação do Museu Índia Vanuíre.

124. 11 abr. 2016, com os indígenas: da TI Vanuíre Ana Paula José, Dirce Jorge Lipu Pereira, José da Silva Campos (Zeca), Mariza Jorge, Sinézio Cotuí, Susilene Elias de Melo; da TI Icatu - Ana Paula Victor Campos, Camila Vaiti Pereira da Silva, Deolinda Pedro e Elenice Francisco Pereira da Silva. Do Museu Índia Vanuíre - Andressa A. de Oliveira, Isaltina S. C. Oliveira, Luis F. Marques, Maria Odete C. V. Rosa, Raquel M. F. M. S. de Luna, Tamimi D. R. Borsatto, Uiara P. Ribeiro e Viviani M. G. B. Justino. E do MAE-USP - Frederico B. Ferreira e Viviane Wermelinger Guimarães.

125. 07 mai. 2016, com as indígenas: Dirce Jorge Lipu Pereira, Lucilene de Melo e Itauany Larissa de Melo da TI Vanuíre; Lidia Campos Iaiati, Maria Rita Campos Rodrigues e Neusa Umbelino da TI Icatu.

126. Cury (2019a).

127. Agradecemos a acolhida no Museu do Índio, Funai; Centro de Documentação de Línguas Indígenas - Celin, Museu Nacional, UFRJ; Museu Regional Ferroviário de Bauru, Prefeitura de Bauru, SP; o Centro 
de Referências Kaingang e Povos Indígenas no Oeste Paulista do Museu Histórico e Pedagógico Índia Vanuíre; e a atenção do Instituto Egon Schaden.

128. Financiamento: MAE-USP, Pró-Reitoria de Pesquisa-USP, CNPq (proc. 44368320158) Projeto Museu - Requalificação de coleções.

129. Cury (2019a).

130. Damy (1983-1984).

131. Cury (2019a).

132. Gleyser, Cledinilson e Gleidson Alves Marcolino. coletados por Schaden em 1947 e doados ao MP em 1951, procedentes da Aldeia Bananal, litoral de São Paulo, entre outros indicados por Damy.

Os Terena requalificaram a Saia de pena de ema (RG4441), os objetos coletados por Baldus em 1947 e os abanos da Coleção Rhodia de 1986.

Para os Kaingang, pela grande quantidade de objetos, foram separados cerâmicas, arcos e flechas, cestaria e objetos relacionados ao sagrado, compreendendo aquilo que foi coletados pela CGGESP, SPI, Baldus e Schultz e outras entradas.

Os grupos se organizaram para uma participação de cerca de 15 indígenas de cada povo, compreendendo a presença de mais velhos, mais novos e jovens, caciques, pajés, assistentes de pajés, pesquisadores indígenas, professores indígenas, estudantes universitários, artesãos, caciques da dança. ${ }^{131}$ Além disso, as mães levaram suas filhas e filhos menores. Os trabalhos, com autorização, foram registrados em vídeos que serão devolvidos aos grupos juntamente com a transcrição. As informações, no entanto, foram repassadas para as etiquetas e textos da exposição autorrepresentativa e serão organizadas no catálogo compartilhado das coleções, reunindo lado a lado as informações etnográficas e as fornecidas pelos indígenas. Desde então, vários encontros ocorreram nas aldeias, quando a requalificação foi se aprofundando com outras contribuições, como acontece também com os trabalhos de restauro de objetos pelos indígenas e trabalhos periódicos que vimos realizando desde a abertura da exposição.

Os Nhandewa se emocionaram ao ver, especialmente, os objetos do batismo e da Casa de reza. Estavam especialmente preocupados com a continuidade cultural, por isso ver as Velas coletadas por Schaden (RG2543 e RG2544) e Baldus (RG2545 e RG2546) e a Pia Batismal (RG4428) foi de grande emoção. A preocupação com a transmissão e continuidade também levou o pajé Nhandewa e seus assistentes ${ }^{132}$ a encontrar uma evidência importante, para a reintrodução do uso do cachimbo na Aldeia Nimuendaju como uma tradição ligada à Casa de reza. Sabendo anteriormente desses objetos, compartilharam conosco outros que haviam preparado para a exposição que, por escolha deles, ficaram ao lado dos objetos ancestrais: velas, uma representação da canoa sagrada em escala reduzida e maquete da Casa de reza, entre outros.

Nas fichas catalográficas preenchidas por T. Hartmann (sem data) temos as descrições:

Pia batismal (RG4428) - "Peça de madeira, toscamente trabalhada em forma de prato, com um pé retangular esculpido na própria madeira". 
Velas (RG2543, RG2544, RG2545 e RG2546) - "Enrolado de pano recoberto de breu ou cerol".

A seguir, a descrição feita pelos Nhandewa, ${ }^{133}$ meses após a requalificação, ${ }^{134}$ para as etiquetas dos objetos (sob a guarda do MAE-USP e outros que prepararam), maquete ${ }^{135} \mathrm{e}$ foto, agrupados por eles na exposição:

- Pia batismal (RG4428) - "Nha'e (Pia batismal) - Vasilha de madeira que guarda a água sagrada, com cascas de ywyráne (pau d'alho) e yary (cedro), é usado no ritual Nimongarai".

- Foto da Pia na Casa de reza na Aldeia Nimuendaju: "Nha'e (Pia): A pia e o altar batismal são os componentes principais para a Cerimônia do Nimongaraí, o batizado". - "Nha'e (Canoa sagrada) - A canoa sagrada é usada com as velas (iraity) no ritual sagradp Nimongaraí, o batismo. É feita de madeira e as velas de tecido de algodão e cera de jataí".

- Velas (RG2543, RG2544, RG2545 e RG2546) - "Iraity (Vela) - A vela sagrada é feita de tecido de algodão e cera de jataí. Ela é usada para espantar espíritos maus e também no ritual sagrado Nimongaraí, o batismo".

- "Iraity (Vela) - A vela sagrada é feita de tecido de algodão e cera de jataí. É usada no ritual sagrado Nimongaraí".

- "O'y gwatsu (Casa de reza) [maquete] - Ela é de sapé, taboa, madeira e taboca. A casa é um lugar de reunião para adorar a Nhanderu (Deus), também é onde acontece o Nimongaraí, o batizado".

No mês de março de 2018, a pedido dos Terena, dois pajés, Ingracia Mendes Cezar e Candido Mariano Elias, um artesão e professor indígena, Afonso Lipu, e dois acompanhantes, Gerolino Cezar lliderança do cacique Jazone de Camilo) e Rosa Lipu Maria (interprete da dona Ingracia) e a pequena Maria Vitória ${ }^{136}$ (filhinha do casal Afonso e Rosa), estiveram no MAE-USP para o restauro da Vestimenta de dança de pena de ema (RG4441) identificada como tal em julho de 2017. Nesse encontro, os Terena reconheceram um conjunto de saia, cocar, braçadeiras e tornozeleiras unidos entre si, amarrados pela fieira. No restauro, as partes foram separadas e ficou composta a vestimenta da dança masculina Hiyokena Kipâe. Tal ação só era possível com a presença dos pajés e permissão obtida por eles e para eles dos encantados para a execução do restauro com a ajuda dos demais, para isso se formou uma equipe inusitada reunida entre 12 e 16 de março com a equipe do MAE-USP também autorizada. A ema e suas penas são sagradas e só podem ser manipuladas pelos homens, nesse trabalho as mulheres foram autorizadas pelos encantados, também pela dona Ingracia ser uma mulher pajé, ou seja, uma escolhida
133. Trabalho do coordenador pedagógico da E. E. I. Aldeia Nimuendaju, Tiago de Oliveira, com as professoras e professores.

134. Os curadores Nhandewa são: Claudino Marcolino Gleyser Alves Marcolino, Creiles Marcolino da Silva Nunes, Tiago de Oliveira, Alício Honório, Claudinei de Lima, Carlos Eduardo Marcolino Honorio, Carolini Carvalho Marcolino Honorio, Cledinilson Alves Marcolino, Cleonice Marcolino dos Santos, Elber Cristiano da Silva, Gleidson Alves Marcolino, Jamile Marcolino, Jederson M. S. dos Santos, João Victor Pereira, Josias Marcolino, Josué Marcolino, Kessy Cristina Marcolino, Kethilin Cristina Marcolino, Larissa Marcolino da Silva, Lucas Onorio Marcolino, Maria da Gloria Marcolino, Natieli Onorio Cruaia, Poliana Vilialba Cezar, Samuel de Oliveira Honorio, Tiago de Oliveira, Vanderson Lourenço, Vanessa Cristina Feliciano e Weriquis Onorio Marcolino.

135. Os objetos foram preparados por artesãos, professores e alunos da Escola Estadual Indígena Aldeia Nimuendaju, exceto as velas que foram preparadas pelo assistente de pajé Gleidson Alves Marcolino. 2017.

136. A criança de colo, cerca de 1 ano, foi mantida no colo da mãe durante todo os dias de trabalho, com a atenção do pai também. 
137. Os curadores Terena são: da Aldeia Ekeruá, TI Araribá - Jazone de Camilo, Ingracia Mendes, Alicio Lipu, Admilson Felix, David da Silva Pereira, Gerolino Cézar, Afonso Lipu, Analu Lipu, Luzia Felix, Natalia Lipu da Silva, Vandriele Daiane da Silva Pereira; da TI Icatu - Rodrigues Pedro, Candido Mariano Elias, Edilene Pedro, Licia Victor, Marcio Pedro, Ranulfo de Camillo; da TI Vanuíre Ana Paula José, Marcio Lipu Pereira Jorge.

138. Parte das informações das etiquetas foram preparadas pela professora Analu Lipu com os alunos do EJA da E. E. I. Aldeia Ekeruá.

139. Os curadores Kaingang são: da TI Icatu - Ronaldo Iaiati, Adriano Cesar Campos, Deolinda Pedro, Neusa Umbelino, Maria Rita Campos, Carlos Roberto Indubrasil, Rosimeire Iaiati Indubrasil, Adriana Victor Rodrigues Campos, Amauri Pedro, Ana Paula Victor Campos, Camila Vaiti Pereira da Silva, Luiz Henrique Indubrasil, Raphael Iaiati, Roberta Iaiati Indubrasil; da TI Vanuíre - Dirce Jorge Lipu Pereira, Susilene Elias de Melo, Ena Luisa de Campos, José da Silva Barbosa de Campos, Mariza Jorge, Itauany Larissa de Melo Marcolino, Ana Carolina Jorge, Joaquim Antônio Jorge, Kauê Lucas de Melo Deodato, Luiz Fernando Jorge, Paloma Jorge, Pedro Henrique de Melo Deodato.

140. Depoimento de José da Silva Barbosa de Campos.

141. Depoimento de José da Silva Barbosa de Campos. pelo mundo espiritual para os trabalhos sagrados da pajelança. As mulheres da equipe do MAE-USP também foram autorizadas. Nesses dias, os Terena presentes, curadores da exposição, ${ }^{137}$ prepararam as informações de todos os textos e etiquetas $^{138}$ para a exposição. $\bigcirc$ conjunto restaurado recebeu um texto sobre os passos, a sequência e evolução, o significado, os papeis do homem e da mulher, os demais objetos como o bombo (pepêké), o bambu (étakati).

Cada grupo tem seu jeito de trabalhar, e seguimos as escolhas deles. Os textos e informações para as etiquetas Kaingang saíram das transcrições das gravações da requalificação (2017), mas outros depoimentos foram gravados e transcritos posteriormente. ${ }^{139}$ Trazemos para conhecimento alguns objetos, como aqueles da CGGESP, admirados pela antiguidade, buscavam conhecer os objetos dos antigos. Os homens Kaingang admiravam os arcos, como o coletado em 1906 pela CGGESP (RG4015):

- "Nô (Arco)

É pesado isso aí. Apoiava no pé e no braço, pra pegá a caça grande. Apoiava e puxava. É diferenciado do arco pequeno, que é pra caçá passarinho, é pra caçá bicho grande, anta. Então, sempre apoiava no pé e puxava.

Inté que tem umas fotos do seu Canuto [Conechu], do seu Juca, tem mais índio lá, os mais antigo. Da história que eles conta, isso era lapidado na base da machadinha, com o tempo começô a trabaiá no facão, depois, chegô no caco de vidro, deixa ela lixada, bem lisa. Vai lapidando.

Hoje, não faiz mais [arco] grande, falta da madera, da devastação que teve. $\mathrm{Na}$ época, tinha muita madera, era na mata. Era muito fácil encontra madera. Hoje a arvera é raro e cê num podê cortá." 140

Sobre o Colar de ossos de ave de 1906 (CGGESP) (No. antigo 5143):

- "Ou ele [o caçador] foi matando e foi juntando ou teve isso [colar] como premiação.

Mas isso tudo vem do dom de Deus. Porque, senão, não teria na aldeia o maior caçador. Sempre tem um que vai e mata. É tudo dom de Deus, o indígena, ele tem isso". 141

A respeito das cerâmicas, também a preferência eram as mais antigas, como a coletada em 1906 pela CGGESP (RG256 1):

$$
\text { - "Kukrõ (Panela) }
$$

A mãe da minha mãe [Catarina] cozinhava o arroz, o peixe, que era mais comida indígena, tudo na panela de barro. Minha vó Chica usava muito negócio de cerâmica. 
Na maior só ponhava jami pra guardá e água. Ela ponhava em cima de uma lata. Furava uma lata de vinte litros, aí, ponhava ela que dava pra ela fica [em pé]". ${ }^{142}$

$\bigcirc$ Kaingang José da Silva Barbosa de Campos (Zeca), pesquisador indígena da TI Vanuíre, se emocionou ao ver a peça feita pela avó Candire, Maria Cecilia de Campos, 1978 (RG13549):

- "Petké (Cerâmica)

Para usar com mel e água, o xibéu.

Eu tinha dez anos, lembro muito bem: "Vó, isso aí [cerâmica] quebrou, tem que jogar fora".

Ela [Candire] falou: "Não, isso não joga fora".

- Mas o que a senhora vai fazer?

- Eu vou voltá ele pro pilão, eu vou socá, eu vou fazê de novo.

- Por que quebrou?

- Porque não tá na lua boa. Eu teimei e fiz isso que não dava certo, que não pediu, não tava firme com Deus.

Então, eu acredito nisso, o porquê do quebrado. E esse quebrado tem corpo, ela socô e fez de novo. Sempre tem uma técnica, um dom que o índio traz, isso nunca acaba. Isso é corpo, isso é vida. Uma história, é corpo e é vida".

Sobre o têxtil denominado como Camisão (RG3285), José da Silva Barbosa de Campos conheceu a peça em 2016, quando se deu a primeira qualificação. Ao perguntar sobre a peça à sua mãe, dona Ena de Campos, esta informou se tratar de uma roupa de parteira. Zeca e Dirce Jorge Lipu Pereira (pajé, kujá, que realizou cinco partos) deram seus depoimentos:

- "Roupa de parteira

Memo entendimento do Pajé, Kujá, [a parteira] tinha, benzia pra protegê. Por isso, todas as crianças que nasciam seriam abençoada. Eles acreditavam assim.

A vó [Candire] foi partera, mas ela nunca usô [essa roupa].

Ser uma partera, a gente [Dirce Jorge] tem o dom que Deus dá. É uma virtude você tá ajudando uma pessoa dá luz, pô uma criança no mundo, você faiz parte de tudo aquilo. Quando você ajuda colocá uma criança no mundo, ele é teu filho. É assim que nóis, parteras, consideramos, nossos filhos. A primera face que ele vê é 
143. Cury (2016b, 2017a; 2018; 2019b; 2020b).

144. Ribeiro (1994).

145. Roca (2015b). da partera, primera coisa que ele sente é as mão da partera, é segunda mãe. É uma virtude muito grande, uma emoção, também, muito grande.

Essa ropa é sagrada e só pode ser feita por um Kujá".

Não por acaso, os objetos que trouxeram grande interesse e emoção entre os três grupos se relacionavam ao sagrado e à espiritualidade. Se a curadoria indígena nos museus traz novas questões à práxis museal, se a questão do sagrado não é nova, pois objetos ritualísticos estão sob a guarda de museus no mundo todo, a questão bastante inusitada para profissionais de museus se refere à espiritualidade e a presença dos encantados que se comunicam com as equipes museais por meio dos pajé, mas têm uma participação efetiva que precisamos considerar na relação entre museus e povos indígenas, ${ }^{143}$ uma vez que, em muitas das situações, eles que dirigiram os trabalhos como os curadores chefe. Estamos nos referindo a novas formas de respeito a que o museu deve quando exerce seu papel com povos indígenas.

\section{CONSIDERAÇÕES FINAIS}

As imbricadas relações entre coleção e exposição não são recentes, como bem colocado, à época, por Berta Ribeiro. ${ }^{144}$ Entretanto, já no início da terceira década do século XXI, novas fronteiras se formam e a colaboração, mesmo com os questionamentos que recebe ${ }^{145}$ ainda é uma boa aposta, como experimentação, pois estabelece claramente as relações mantidas ou em construção entre museus e povos indígenas. Há um jogo de força que precisa ser explicitado e tratado, quanto a isso não há objeção, ou seja, não há volta, a participação indígena no museu é um processo sem retorno.

A experiência apresentada reside na descolonização como uma opção a mais para os museus, mas uma opção promissora para os museus etnográficos e outros que salvaguardam o patrimônio indígena, com destaque também aos museus de arqueologia. $\bigcirc$ processo em pauta teve como estratégia a elaboração de uma exposição, envolvendo os agentes indígenas em uma ação museal de visibilidade para suas realidades atuais. A exposição é uma ação de curadoria que tem a capacidade de articular toda a curadoria como processo em torno do objeto museológico. Ainda, a exposição é a possibilidade na comunicação museológica de grande alcance público. No artigo, então, passamos pelas condições de produção no eixo gestão institucional, coleções e coletores, relatórios e registros documentais, para localizar os 
objetos etnográficos relacionados às coleções Kaingang, Guarani Nhandewa e Terena, mas também informar sobre os mais diversos procedimentos adotados no passado e suas implicâncias no presente. À trajetória dos objetos do "campo" ao museu, foram trazidas as contribuições dos agentes indígenas paulistas para a visibilidade que querem ter, lembrando os direitos indígenas aos processos de musealização e como o museu pode trabalhar para a inclusão social.

No que se refere aos documentos consultados, os inventários diversos foram alterando sua linguagem. Por exemplo, o Livro de Tombo de 1914 tem uma escrita descritiva que nos permite uma visão de época sobre o processo de colonização do oeste paulista, a intervenção do SPI e a reunião de inúmeros grupos Kaingang com suas chefias em um único aldeamento, posteriormente, duas Terras Indígenas - Icatu e Vanuíre. O Inventário 7, por sua vez, usa a denominação do objeto. $\bigcirc$ Registro Geral da Secção de Etnologia do Museu Paulista (Livro Marrom) usa uma nova numeração, o Registro Geral (RG), o que indica também uma "escrita etnográfica" incorporada pós criação da Seção de Etnologia por Herbert Baldus. O Registro Geral da Seção de Etnologia (sem data, tamanho A3) acrescenta mais dados de catalogação no mesmo documento. A desagregação de numerações anteriores com $\circ R G$, na documentação e nas peças, acarreta problemas de identificação e localização de peças, ou seja, em algumas situações estão separadas as descrições feitas no passado e as classificações etnográficas mais recentes. A cada novo documento de registro das coleções etnográficas, há contribuições, mas também perdas e erros. Um exemplo do que não pode ser omitido ou esquecido: "Craneo de indio Coroado 60 annos capitão morto por ocasião do assalto que os indios fizeram a 31 de julho de 1906 na faa [...] da Corredeira, mun. Baurú _ SP [...] Otto Dreher leg. XI O6 - [...] documento [...] A7 Archivo" (Livro de Tombo 1914, p. 34-35, números 111 10-1 11 1)". Os Kaingang têm direito de saber sobre a história do seu povo no território que ocupava (Figura 1), manifestar seus sentimentos com relação aos remanescentes humanos de seus antepassados e se amparar nos seus direitos. ${ }^{146}$

Todos esses aspectos sobre a documentação e tantos outros estão sendo reunidos no inventário em desenvolvimento pela Divisão de Apoio à Pesquisa e Extensão do MAE-USP, agora com o suporte da tecnologia da informação e uma base de dados. Nesse sentido, o estudo de curadoria das coleções Kaingang, Guarani Nhandewa e Terena em São Paulo é uma parcela de um trabalho maior de anos e com muitas outras contribuições.

A participação dos grupos indígenas no estudo de curadoria, a requalificação das coleções, foi um trabalho bastante eficaz, para os grupos Kaingang, Guarani
146. Pereira; Melo (2020), Cury (2020a). 
147. Roca (2015a).

148. Cury (2016a)
Nhandewa e Terena, suas memórias e relações intergerações, entre tantos outros aspectos. $\bigcirc$ material gravado e transcrito será convertido em três livros. Mas a requalificação foi eficaz para o MAE-USP para aquisição de valores, metodologias e novos protocolos de trabalho, mas também valorização das ações em curso, com os vários agradecimentos dos indígenas pelos cuidados da equipe com os objetos. A partir da requalificação, a opção descolonial será ativada no catálogo compartilhado que será organizado, reunindo informações etnográficas obtidas em publicações e teses, com as informações dos grupos indígenas, representação e autorrepresentação, respeitando-se suas lógicas e linguagens.

No processo colaborativo com indígenas integrados ao convívio no museu, há inúmeras considerações a serem feitas, especialmente quanto aos limites e alcances das ações dessa natureza participativa. Na relação entre pesquisadores e indígenas transposta para museu e indígenas na colaboração, como é construída a confiança? Uma vez que há o museu que precisa mudar, pois já não atende às demandas sociais e civis, como as relações de confiança se estabelecem sucessivamente, considerando que o museu ainda está pouco preparado para atender aos direitos indígenas. Há espaço para a confiança na relação entre museu e indígenas? Há uma relação pautada no colonialismo de cinco séculos que precisa ser desconstruída, como também que essa relação se estabelece num jogo de forças, a questão central é o quanto o jogo de força busca o equilíbrio da indigenização do museu. ${ }^{147}$ Ainda, a soberania indígena é possível na curadoria e, no limite, no museu? Os campos antropológico e museológico estão preparados para a soberania indígena no museu? Como a autoridade do museu se recoloca nessa transformação?

No que se refere a uma nova ética, precisamos construíla, pois novas relações estabelecem novos códigos de conduta para todos os profissionais envolvidos em processos colaborativos. Mas, objetivamente, a gestão de coleções reúne uma problemática que deve ser revisitada a partir das novas circunstâncias museais que se formam, naquilo que concerne ao registro e coleta de objetos. Afinal, os direitos indígenas devem pautar o museu, para que novas políiticas de gestão de acervos orientem novos procedimentos ${ }^{148}$ e para que a curadoria museológica se amplie com a colaboração.

Os manuais de documentação museológica não mais se sustentam nos novos parâmetros, por isso uma revisão pautada em novos princípios devem se colocar, substituindo práticas curatoriais colonizadoras, sem o esquecimento de que as políticas públicas museais precisam se aperfeiçoar nesse sentido, pois os manuais se organizam na legislação e na ética. 
A descolonização das práticas já vem acontecendo, ${ }^{149}$ como também a curadoria compartilhada, ${ }^{150}$ mas também as redes internacionais se formam para informar os indígenas acerca de seus patrimônios musealizados ${ }^{151}$ e a etnomuseologia e as interlocuções com os indígenas ${ }^{152}$ vêm avançando com novas experimentações. A qualificação de coleções já faz parte da rotina do Museu do Índio ${ }^{153}$ como tantas iniciativas já se realizaram e/ou estão em curso. ${ }^{154} \bigcirc$ momento a seguir, então, é o de discussão ampliada, para que as boas práticas e novas práticas curatoriais que respeitem os direitos indígenas no museu e pelo museu se estabeleçam em definitivo.
149. A exemplo do que propõem Pacheco de Oliveira Fo.; Santos (2019).

150. A exemplo de Garcés; Françozo; Broekhoven; Ka'apor (2017).

151. Velthem; Kukawka; Joanny (2017).

152. Lima (2012), Shepard Jr.; Garcés; Robert; Chaves (2017).

153. Couto (2016).

154. Uma relação se encontra em Cury (2017b) 


\section{REFERÊNCIAS}

FONTES IMPRESSAS

Relatórios consultados na Revista do Museu Paulista (em ordem cronológica crescente)

IHERING, Hermann von. O Museu Paulista nos annos de 1903 a 1905. Revista do Museu Paulista, v. VII, p. 1-30, 1907.

IHERING, Hermann von. A questão dos índios no Brazil. Revista do Museu Paulista, v. VIII, p. 112-140, 1911.

IHERING, Hermann von; IHERING, Rodolpho von. O Museu Paulista nos annos de 1906 a 1909. Revista do Museu Paulista, v. VIII, p. 1-22, 1911.

Relatórios consultados na Revista do Museu Paulista, N.S. (em ordem cronológica crescente)

BALDUS, Herbert. Relatório da Seção de Etnologia. Revista do Museu Paulista, N. S., São Paulo, v. 2, p. 305-308, 1948.

BALDUS, Herbert. Relatório da Seção de Etnologia. Revista do Museu Paulista, N. S., São Paulo, v. 4, p. 471-476, 1950.

BALDUS, Herbert. Relatório da Seção de Etnologia. Revista do Museu Paulista, N. S. n. 5, p. 281-285, 1951.

BALDUS, Herbert. Relatório da Seção de Etnologia. Revista do Museu Paulista, N. S., São Paulo, v. 6, p. 527-33, 1952.

BALDUS, Herbert. Relatório da Seção de Etnologia. Revista do Museu Paulista, N. S., São Paulo, v. 7, p. 419-28, 1953.

BALDUS, Herbert. Relatório da Seção de Etnologia 1956. Revista do Museu Paulista, N. S. n. 11, 1959. v. XI, p. 317-321, 1959.

Noticiário do Museu Paulista. Revista do Museu Paulista, N.S., v. XXVI, 1979 


\section{INVENTÁRIOS CONSULTADOS (EM ORDEM CRONOLÓGICA CRESCENTE)}

Livro de Tombo 1914. Museu Paulista. Acervos: Arqueológicos e Etnográficos.

Catálogo II - Colleções Anthropologica e Ethnografica INV. 14. Livro de entrada Ethnographia e Anthropologia / Archeologia. "Museu Paulista 5.II-1914".

Inventário do Museu Paulista - Livro 1 (São Paulo, 9 de fevereiro de 1916).

Inventário do Museu Paulista no. 4 (São Paulo, 22 de fevereiro de 1916).

Inventário 7 (1o. de dezembro de 1932, assinado por Affonso de E. Taunay) - Inventário do material exposto a visita pública nas diversas salas do Museu Paulista das Secções de História e Etnografia.

Registro Geral da Secção de Etnologia do Museu Paulista, sem data, posterior a 1947, déc. 1950 - Livro de Capa Marrom

Registro Geral da Seção de Etnologia, sem data, tamanho A3.

\section{DOCUMENTOS CONSULTADOS}

Documentos 8, 15, 16, 19, 57, 78, 109, 79/01670.

Documento MAE00493, 1950 - Permuta com o American Museum of Natural History.

Documento MAE00489, 1956 - Permuta com o Real Instituto Tropical de Amsterdam.

Exchange with Museu Paulista, São Paulo Brasil - North American Indian Ethnological Collection [American Museum of Natural History].

LIVROS, ARTIGOS E TESES:

BALDUS, Herbert. Harald Schultz 1909-1966. Revista do Museu Paulista, N. S., n. XVI, p. 7-20, 1965-1966. 
BALDUS, Herbert. Lendas dos índios Tereno. Revista do Museu Paulista, N. S., v. IV, p. 217232, 1950.

BALDUS, Herbert. Revista do Museu Paulista. Boletim Bibliográfico. São Paulo: Biblioteca Pública Municipal, Departamento de Cultura, v. XII, p. 169-171, 1949. Disponível em: <https:// bit.ly/3i0FXiI>. Acesso em: 23 jun. 20.

BARBOSA, Luiz Bueno Horta. A pacificação dos Kaingangs paulistas: hábitos, costumes e instituições desses índios. 2a. ed. Jaú: Códices, 2019.

BITTENCOURT, Vera Lúcia Nagib. Revista do Museu Paulista e(m) capas: identidade e representação institucional em texto e imagem. Anais do Museu Paulista, v. 20, n. 2, p. 149$184,2012$.

COUTO, Ione Helena Pereira. Desenvolvimento e gestão das coleções etnográficas do Museu do Índio: 1942 aos dias de hoje. In: CURY, Marília Xavier. (org.). Direitos indígenas no museu - Novos procedimentos para uma nova política: a gestão de acervos em discussão. São Paulo: Secretaria da Cultura: ACAM Portinari: Museu de Arqueologia e Etnologia da Universidade de São Paulo, 2016. p. 62-75.

CURY, Marília Xavier. Repatriamento e remanescentes humanos: musealia, musealidade e musealização de objetos indígenas. Em Questão, v. 26, p. 14-42, Edição Especial Dossiê Patrimônio e Culturas Tradicionais, 2020a.

CURY, Marília Xavier. Metamuseologia: Reflexividade sobre a tríade musealia, musealidade e musealização, museus etnográficos e participação indígena. Museologia E Interdisciplinaridade, v. 9 , n. 17 , p. $129-146,2020$ b.

CURY, Marília Xavier. Museu e exposição - O exercício comunicacional da colaboração e da descolonização com indígenas. In: Museu Goeldi: 150 anos de ciência na Amazônia. Belém: Museu Paraense Emílio Goeldi, 2019a. p. 313-348.

CURY, Marilia Xavier. The sacred in museums, the Museology of the sacred: the spirituality of indigenous people. ICOFOM Study Series, n. 47, p. 89-104, $2019 \mathrm{~b}$.

CURY, Marília Xavier. La museología y lo sagrado - La resacralización del museo. In: MAIRESSE, F. (ed.). Museology and the sacred. Materials for the discussion. Paris: Icofom, 2018. p. 60-64.

CURY, Marília Xavier. Lições Indígenas para a descolonização dos Museus - Processos comunicacionais em discussão. Cadernos Cimeac, v. 7, n. 1, p. 184-211, 2017 a.

CURY, Marília Xavier. Circuitos museais para a visitação crítica: descolonização e protagonismo indígena. Revista Iberoamericana de Turismo, v. 7, p. 87-113, $2017 \mathrm{~b}$. 
CURY, Marília Xavier. Direitos indígenas no museu - Novos procedimentos para uma nova política: a gestão de acervos em discussão - Introdução. In: CURY, Marília Xavier. (org.). Direitos indígenas no museu - Novos procedimentos para uma nova política: a gestão de acervos em discussão. São Paulo: Secretaria da Cultura: ACAM Portinari: Museu de Arqueologia e Etnologia da Universidade de São Paulo, 2016a. p. 12-22.

CURY, Marília Xavier. Relações (possíveis) museus e indígenas - em discussão uma circunstância museal. In: LIMA FILHO, Manuel. Ferreira.; ABREU, Regina.; ATHIAS, Renato. (org.). Museus e atores sociais: perspectivas antropológicas. Recife: UFPE: ABA, 2016b. p. 149-170.

DAMY, Antonio S. A. O acervo Guarani do Museu Paulista: contribuição para a classificação sistemática. Revista do Museu Paulista, N. S., v. XXIX, p. 217-273, 1983-1984.

DAMY, Antonio S. A. Materiais etnográficos brasileiros na Suiça. Revista do Museu Paulista, N. S., v. XXXI, 1986, p. 211-219.

DAMY, Antonio S. A.; HARTMANN, Thekla. As coleções etnográficas do Museu Paulista: composição e história. Revista do Museu Paulista, N. S., v. XXXI, p. 223-247, 1986.

DEBLASIS, Paulo A. D.; MORALES, Walter F. O potencial dos acervos antigos: recuperando a coleção 030 do Museu Paulista. Revista do Museu de Arqueologia e Etnologia, São Paulo, n. 7, p. 111-131, 1997.

DELISS, Clementine. Collecting Life's Unknows. In: L'INTERNATIONALE (ed.) Decolonising Museums [online], 2015. p. 23-34.

EDITORIAL. Herbert Baldus (1899-1970). Revista do Museu Paulista, N. S., v. XVIII, 1968-1969.

FRANÇOZO, Mariana. O Museu Paulista e a história da antropologia no Brasil entre 1946 e 1956. Revista de Antropologia, v. 48, n. 2, p. 585-612, 2005.

FRANÇOZO, M.; Broekhoven, Laura Van. Dossiê "Patrimônio indígena e coleções etnográficas". Boletim do Museu Paraense Emílio Goeldi: Ciências Humanas, v. 12, n. 3, 709-711, 2017.

GARCÉS, Claudia Leonor López; FRANÇOZO, Mariana; BROEKHOVEN, Laura Van; KA'APOR, Valdemar. Conversações desassossegadas: diálogos sobre coleções etnográficas com o povo indígena Ka'apor. Boletim do Museu Paraense Emílio Goeldi. Ciências Humanas, v. 12, n. 3, p. 713-734, set.-dez.2017.

HARTMANN, Thekla. O enterro de Curt Nimuendaju (1883-1945). Revista do Museu Paulista, N. S., n. 28, p. 187-190, 1981-1982. 
HARTMANN, Thekla; COELHO, Vera Penteado. Contribuições à antropologia em homenagem ao Professor Egon Schaden. São Paulo: Museu Paulista, 1981. (Coleção Museu Paulista, Série Ensaios, v. 4).

IHERING, Hermann von. A questão dos índios no Brazil. Revista do Museu Paulista, v. VIII, p. 112-140, 1911.

KASTNER, Klaus-Peter. As coleções brasileiras do Museu Estatal de Etnologia de Dresden. Revista do Museu de Arqueologia e Etnologia, n. 1, p. 147-163, 1991.

LIMA, Nei Clara de. O Museu Antropológico da UFG e a interlocução com povos indígenas. In: CURY, Marília. Xavier.; VASCONCELLOS, Camilo. de. Mello.; ORTIZ, Joana Montero. (org). Questões indígenas e museus: debates e posibilidades. São Paulo: Secretaria da Cultura: ACAM Portinari: Museu de Arqueologia e Etnologia da Universidade de São Paulo, 2012. p. 71-77.

MUSEU PAULISTA. Guia pelas collecções do Museu Paulista. São Paulo: Museu Paulista, 1907.

PACHECO DE OLIVEIRA Fo., João; SANTOS, Rita de Cássia Melo. Descolonizando a ilusão museal - etnografia de uma proposta expositiva. In: PACHECO DE OLIVEIRA Fo., João; SANTOS, Rita de Cássia Melo. (org.). De acervos coloniais aos museus indígenas: formas de protagonismo e de construção da ilusão museal. João Pessoa: UFPB, 2019. p. 397-434.

PAZINATTO, Renata Parada. Coleções etnográficas no interior do estado de São Paulo: composição e história. Revista do Museu Paulista, N. S., v. 32, p. 263-304, 1987.

PEREIRA, Dirce Jorge Lipu; MELO, Susilene Elias de. Ética - remanescentes humanos em museus. In: Cury, Marília. Xavier. (org.). Museus etnográficos e indígenas: aprofundando questões, reformulando ações. São Paulo: SEC-SP, ACAM Portinari, Museu Índia Vanuíre, MAE-USP, 2020.

RIBEIRO, Berta. Etnomuseologia: da coleção à exposição. Revista do Museu de Arqueologia e Etnologia, n. 4, p. 189-201, 1994.

RIBEIRO, Darcy. Os Kaingáng e a expansão dos cafezais. In: Os índios e a civilização: a integração das populações indígenas no Brasil moderno. São Paulo: Círculo do Livro, 1988. p. 93-98.

ROCA, Andrea. Acerca dos processos de indigenização dos museus: uma análise comparativa. Mana, v. 21, n. 1, p. 123-155, $2015 a$.

ROCA, Andrea. Museus indígenas na Costa Noroeste do Canadá e nos Estados Unidos: colaboração, colecionamento e autorrepresentação. Revista de Antropologia, v. 58, p. 117-142, 2015b.

SAMPAIO-SILVA, Orlando. O antropólogo Herbert Baldus. Revista de Antropologia, v. 43, n. 2, p. 24-79, 2000. 
SCHADEN, Egon. Notas sôbre a vida e a obra de Curt Nimuendajú. Revista de Antropologia, v. 15 e 16, p. 77-89, 1967-1968.

SCHUMANN, Leonor; HARTMANN, Thekla. Coleções etnográficas brasileiras em Stuttgart: histórico e composição. Revista do Museu de Arqueologia e Etnologia, n. 2, p. 125-132, 1992.

SHEPARD JR., Glenn H., GARCÉS, Claudia Leonor López; ROBERT, Pascale de, CHAVES, Carlos Eduardo. Objeto, sujeito, inimigo, vovô: um estudo em etnomuseologia comparada entre os Mebêngôkre-Kayapó e Baniwa do Brasil. Boletim do Museu Paraense Emílio Goeldi. Ciências Humanas, v. 12, n. 3, p. 765-787, set.-dez. 2017.

SILVA, Fabíola Andréa. Arqueologia colaborativa com os Asurini do Xingu: Um relato sobre a pesquisa no igarapé Piranhaquara, T.I. Koatinemo. Revista de Antropologia, n. 2, p. 143-172, 2015.

SILVA, Fabíola Andréa. O plural e o singular das arqueologias indígenas. Revista de Arqueologia, v. 25, n. 2, 2012.

VELOSO JÚNIOR, Crenivaldo Regis. Índice de objetos, índice de histórias: o catálogo geral das coleções de antropologia e etnografia do Museu Nacional. Ventilando Acervos, v. especial, n. 1, p. 71-89, 2019.

VELTHEM, Lucia Hussak van; KUKAWKA, Katia, JOANNY, Lydie. Museus, coleções etnográficas e a busca do diálogo intercultural. Boletim do Museu Paraense Emílio Goeldi. Ciências Humanas, v. 12, n. 3, p. 735-748, set.-dez. 2017.

Artigo apresentado em: 14/7/2020. Aprovado em: 12/11/2020.

\section{(cc) BY}

